\title{
REVIEWS
}

\section{Polymer Structure Control Based on Crystal Engineering for Materials Design}

\author{
Akikazu Matsumoto ${ }^{\dagger}$ \\ Department of Applied Chemistry, Graduate School of Engineering, Osaka City University, \\ and PRESTO, Japan Science and Technology Corporation (JST), \\ Sugimoto, Sumiyoshi-ku, Osaka 558-8585, Japan.
}

(Received November 30, 2002; Accepted January 8, 2003)

\begin{abstract}
In this review article, polymer structure control and organic material design based on polymer crystal engineering are described. The structures and properties of crystalline materials are designed using pre-organized molecules through various intermolecular interactions such as hydrogen bonds, $\pi \cdots \pi, \mathrm{CH} / \pi, \mathrm{CH} / \mathrm{O}$, and halogen interactions. Here, we describe the features and mechanisms of the topochemical polymerization of 1,3-diene monomers including some ester, ammonium, and amide derivatives of muconic and sorbic acids, which are 1,3-diene di- and monocarboxylic acid derivatives, respectively. We have proposed the topochemical polymerization principles for diene monomers on the basis of the crystallographic data accumulated for various kinds of diene monomers. The combination of several intermolecular interactions is useful for the construction of molecular packing appropriate for $5 \AA$ stacking in order to facilitate the topochemical polymerization in the crystalline state. We refer to the control of polymer chain structure including tacticity, molecular weight, and ladder structure, and also polymer crystal structures, as well as the organic intercalation system using layered polymer crystals obtained by the topochemical polymerization. A totally solvent-free system for the synthesis of layered polymer crystals is also described.

KEY WORDS Topochemical Polymerization / Solid-State Reaction / Crystal Engineering / Supramolecular Synthon / Stereoregular Polymer / Controlled Radical Polymerization / X-Ray Single Crystal Structure Analysis / Intercalation /
\end{abstract}

Controlled polymer synthesis, including the control of polymer chain structures such as molecular weight, molecular weight distribution, chain-end structure, branching, regioselectivity, and stereoselectivity, has great potential for the design of macromolecular architecture leading to advanced nano-materials and devices. ${ }^{1-11}$ All the features and functions of polymers importantly depend on primary chain structures and the manner of polymer chain assembly in crystalline and non-crystalline solids, or in a condensed state. Therefore, the control of polymer chain structures in polymer synthesis can hardly be overestimated for the architecture of advanced polymeric materials.

Especially, the stereochemistry of polymers has received significant attention in both fundamental and applied fields ever since the first discoveries of stereoregular polymers in the $1950 \mathrm{~s} .{ }^{12-14}$ Highly controlled stereospecific polymerization has been well established by coordination polymerization of olefins and diene monomers and by anionic polymerization of certain types of polar monomers. Radical polymerization is the most important and convenient process for the production of various kinds of vinyl and diene polymers due to recent achievements in well-controlled polymer- izations in addition to the classical advantages of the radical process. ${ }^{15-22}$ There are two fundamentally different ways to control of the chain structure during freeradical polymerization. One is the control of the propagating chain end using specially designed monomers, catalysts, Lewis acids, and chiral auxiliaries, and another is the use of polymerizations in organized media. Polymerization in organized media is used for the threedimensional structure control of polymers and their assembly in constrained media such as layers, channels, and solid surfaces.

Topochemical polymerization, which is one of the most important functions of crystalline materials, is the specific crystal-to-crystal reaction to give a unique chain structure and a polymer single crystal that cannot be manufactured by solution polymerization or by recrystallization of a preformed polymer from its solution or melt. Namely, the topochemical polymerization of organized monomers is useful not only for the control of tacticity but also for the fabrication of polymer composites designed on the basis of supramolecular architecture and crystal engineering. It is well known that some limited diacetylene and diolefin monomers undergo topochemical polymerization, ${ }^{23-26}$ but other

†T whom correspondence should be addressed (Fax: +81-6-6605-2981, E-mail: matsumoto@a-chem.eng.osaka-cu.ac.jp). 


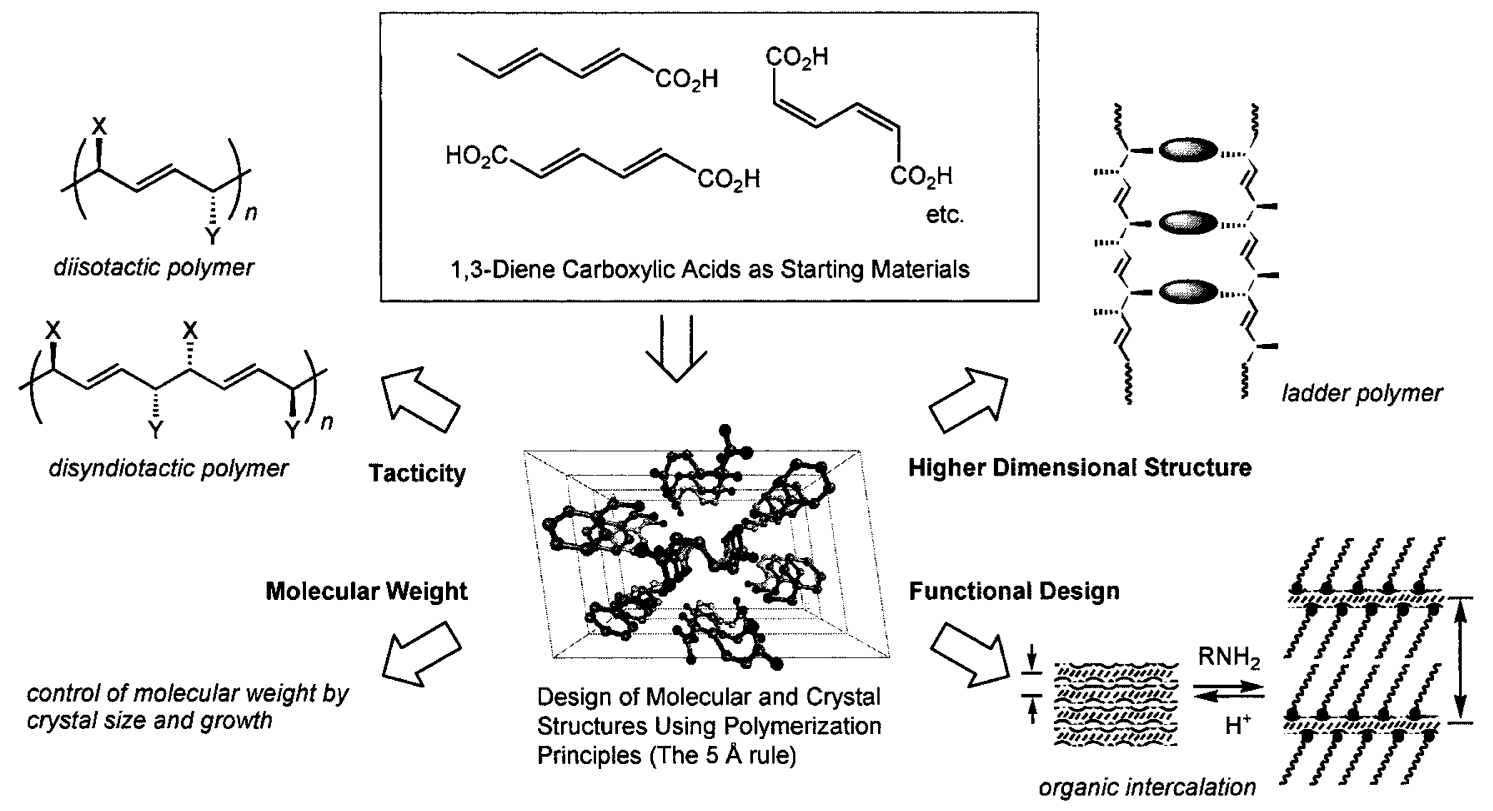

Figure 1. Control of polymerization reactivity and polymer structure through molecular and crystal structure design from 1,3-diene carboxylic acid derivatives.

monomers have not been believed for a long time to polymerize in a topochemical manner. In fact, no designer crystal has been reported for the 1,3-diene monomers, despite the pioneering works on the solidstate polymerizations regarding inclusion polymerizations $^{27-30}$ since the 1960s and the radiation polymerization of several layered compounds ${ }^{31-36}$ in the 1980s.

During the recent decade, we have revealed the features and mechanisms of the polymerization of various 1,3-diene monomers, ${ }^{37,38}$ including the esters, the amides, and the alkylammonium salts of $(Z, Z)$ - or $(E, E)$-muconic and sorbic acids, via a topochemical reaction mechanism in the crystalline state, and the characterization of the obtained polymer crystals as a new category of organic solids (Figure 1).

\section{RECENT PROGRESS IN THE POLYMERIZATION OF 1,3-DIENE MONOMERS IN THE CRYSTALLINE STATE}

In 1994, Matsumoto et al. discovered a topochemical polymerization of conjugated 1,3-diene monomers giving a stereoregular polymer in the form of polymer crystals. ${ }^{39}$ When diethyl $(Z, Z)$-muconate (1a) was photoirradiated in the crystalline state, a meso-diisotactictrans-2,5 (tritactic) polymer was produced, in contrast to the formation of an atactic polymer by conventional radical polymerization in an isotropic state (Scheme 1).

Thereafter, we have comprehensively investigated the design of monomers, the crystal structure analysis of monomers and polymers, and polymerization reactivity control to reveal the entire features of the

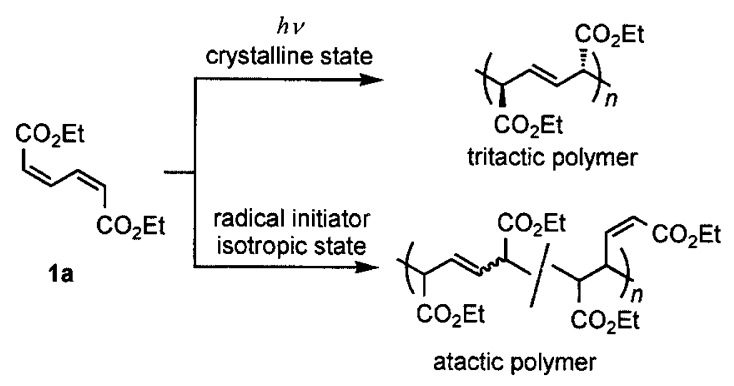

Scheme 1.

topochemical polymerization of 1,3-diene monomers. Table I summarizes the chemical structures of the topochemically polymerizable 1,3-diene monomers ever reported by our and other groups. The chemical structures of these polymerizable monomers imply common structures, benzyl groups with methyl, methoxy, or halogen substituents, a naphthylmethyl group, and long alkyl chains.

The topochemical polymerization of 1,3-diene monomers is induced by the irradiation of UV-, X-, and $\gamma$-rays, or upon heating, similar to the solid-state polymerization of diacetylene compounds. The polymerization occurs not only for some esters of muconic acid but also for the ammonium and amide derivatives of muconic and sorbic acids when long-alkyl, benzyl, and naphthylmethyl groups are introduced as the $\mathrm{N}$ substituents (Scheme 2).

For example, the ethyl and halo- or methoxybenzyl esters of $(Z, Z)$-muconic acid polymerize $(\mathbf{1 a}-\mathbf{1 d})$ to give the corresponding diisotactic polymers, ${ }^{40-42}$ while most of the other ester derivatives isomerize to the corresponding $E E$ isomers or have no reaction. 
Table I. Chemical structure of topochemically polymerizable 1,3-diene monomers

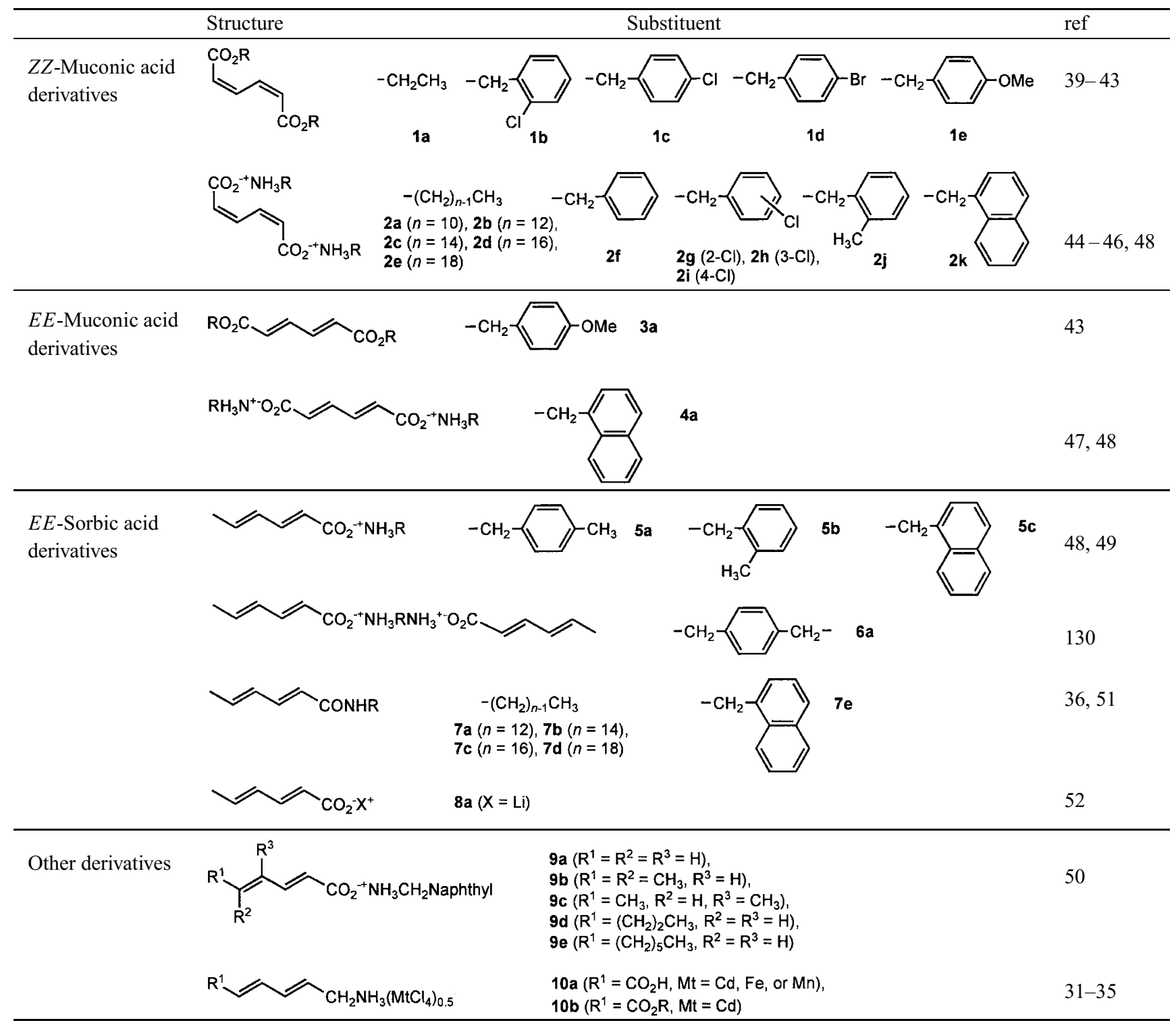

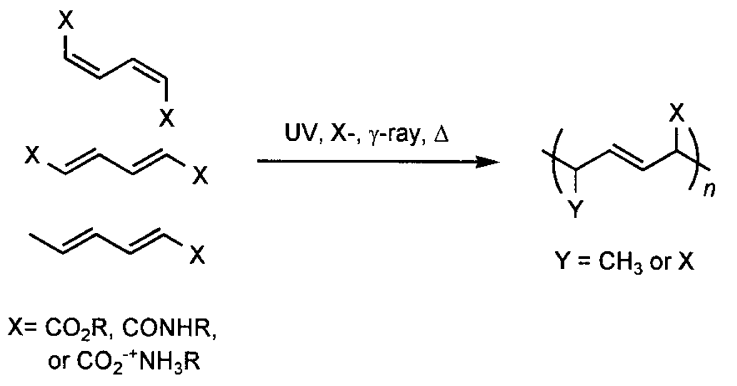

Scheme 2.

The 4-methoxybenzyl ester of $(E, E)$-muconic acid (3a) provides a disyndiotactic polymer with a structure identical to that obtained from the $(Z, Z)$-muconic ester (1e). ${ }^{43}$ Similarly, some ammonium derivatives of $(Z, Z)$-muconic acid topochemically polymerize (2a2k), ${ }^{44-46}$ several others isomerize, and all the others are photo-inactive. The corresponding ammonium $(E, E)$-muconates are stable under photoirradia- tion except for di(1-naphthylmethylammonium) $(E, E)$ muconate (4a), which readily polymerizes similarly to the $(Z, Z)$-muconate one $(\mathbf{2 k}) .^{47,48}$ The polymerization of the ammonium derivatives of sorbic acid has also been revealed (5a-5c and $\mathbf{6 a}) .{ }^{48,49}$ A naphthylmethylammonium group is very useful for the design of various polymerizable 1,3-diene monomers other than muconic and sorbic acids but also for other types of 1,3diene carboxylic acids $(9 \mathbf{a}-9 \mathbf{e}){ }^{50}$ In contrast to the results of the successful polymerization of the ammonium and ester derivatives during the recent decade, no polymerization has been reported for the amide derivatives of the 1,3-diene carboxylic acids except for only the case of $N$-octadecylsorbamide (7d). ${ }^{36}$ In the beginning of the 1980s, Tieke first reported the topochemical polymerization of some compounds derived from sorbic acid with a perovskite layered structure (10a and 10b), ${ }^{31-35}$ and also referred to the $\gamma$-radiation polymerization of $7 \mathbf{d} .^{36}$ The polymerization mechanism and 
crystal structure of the amide derivatives and the characterization of the resulting polymer had still been undetermined over the past two decades. Very recently, we have confirmed that the topochemical polymerization proceeds under UV- and $\gamma$-radiation in the crystalline state when naphthylmethyl and higher $n$-alkyl groups are introduced as the $N$-substituent of the amide derivatives as expected (7a-7e) ${ }^{51}$ The solid-sate polymerization of lithium sorbate (8a) was reported in 1996 by Schlitter and Beck. ${ }^{52}$

Most of the topochemical reactions, including our first finding of the topochemical polymerization of 1a have been found accidentally or beyond any expectation. ${ }^{38,39}$ During subsequent and extensive investigation, numerous studies have been carried out by trialand-error approaches to establish any empirical rule accounting for a correlation between the geometry of functional moieties and reactions in the solid state. The sophisticated control of molecular stacking for any function or reaction is required, but still lacking at present. This is due to the difficulty in the design of crystal structures ideal for the functions and reactions in the crystalline state. In fact, trying to establish a priori exactly how molecules come together in the crystals (crystal structure prediction) is known to be one of the unsolved problems and challenging topics in modern science. ${ }^{53-57}$ Reluctantly, we have to accept the fact that it is difficult to accurately predict any molecular packing and also any reactivity of molecules in the crystalline state from chemical structure information. Similarity in the structure of homologous molecules often results in a greatly alternative molecular packing and reactivity in the solid state. In this respect, the reactivity in the solid state is much different from the readily predictable reactivity of molecules in a solution. The reactivity of molecules is controlled in the crystalline state by the crystal packing structure as opposed to by the chemical nature of the molecules. Of course, continuous efforts have been made to overcome the difficulty in the crystal structure and the reactivity controls of the solids. Eventually, recent eminent ideas based on crystal engineering and supramolecular chemistry ${ }^{58-62}$ lead us to design and control of the crystal structures, the properties, and the reactivity of organic molecules in the solid state.

\section{REACTION MECHANISM OF TOPOCHEMICAL POLYMERIZATION OF 1,3-DIENE MONOMERS}

The process of topochemical polymerization of 1,3diene monomers is independent of the kind of energy for initiation to form radicals as the propagating species and of the environment surrounding the crystals. The polymerization proceeds under photo-, ${ }^{41} \mathrm{X}-,{ }^{63}$ and $\gamma$ ray $^{64}$ irradiation, or upon heating ${ }^{65}$ in the dark in vacuo, in air, or even in water or organic solvents as the dispersant (non-solvent) for the crystals. Previously, it has been reported that the different reaction modes induced by the different activated species depending on the type of radiation of the same 1,3-diene compounds. ${ }^{66}$ In a series of muconic and sorbic acids, however, a single product has been obtained from one monomer independent of the radiation conditions unless polymorphs are present. This is because the reaction path is exclusively controlled by the crystal lattice in the solid state, but not by the chemical nature and the radiation conditions.

We have reported that some monomers are polymerized by UV-, X-, and $\gamma$-ray irradiation in the crystalline state since the finding of the polymerization of $\mathbf{1 a}$, spontaneously and accidentally induced by scattered light in a room. However, no thermally-induced polymerization has been detected until recently. The reason is simply because many polymerizable monomers melt or decompose upon heating; the melting point is $53^{\circ} \mathrm{C}$ for $1 \mathrm{a}$, and the ammonium derivatives such as 2f and 5a decompose over $100^{\circ} \mathrm{C}$. Very recently, Nagahama et al. firmly determined the thermally-induced topochemical polymerization of the bifunctional ammonium monomer $\mathbf{6 a}$ and the ester monomer $\mathbf{1 c}$, which have high decomposition and melting points of over $160{ }^{\circ} \mathrm{C}$ and $131{ }^{\circ} \mathrm{C}$, respectively. ${ }^{65}$ The polymer yield increases as the reaction temperature increases during the thermal polymerization. IR and NMR spectroscopies confirmed that the polymers obtained from the thermally-induced polymerization in the dark have a stereoregular meso- or erythro-diisotactic-trans-2,5repeating structure identical to the photopolymers produced by UV- or $\gamma$-ray irradiation. The propagation is determined under the strict control of the crystal lattice during the thermally-induced polymerization.

The rate constants of the polymerization of $6 \mathbf{a}$ were $8.8 \times 10^{-6}$ and $1.1 \times 10^{-4} \mathrm{~s}^{-1}$ at $100^{\circ} \mathrm{C}$ in the dark and with UV irradiation, respectively. The rate of the polymerization under photoirradiation conditions is over 10 times faster than that in the dark. The rate of photopolymerization depends on the polymerization temperature, despite the photo-initiating system of the polymerization. The polymer yield reaches a quantitative yield during the UV irradiation within several hours at a relatively high temperature, but it gradually decreases with decreasing polymerization temperature. The polymer yield of the photoirradiation below room temperature was very low. The overall activation energy was large at approximately $55 \mathrm{~kJ} \mathrm{~mol}^{-1}$ for the photopolymerization of 1a. The activation energy for the propagating reaction is assumed to be small because an ultrahigh 
(a)

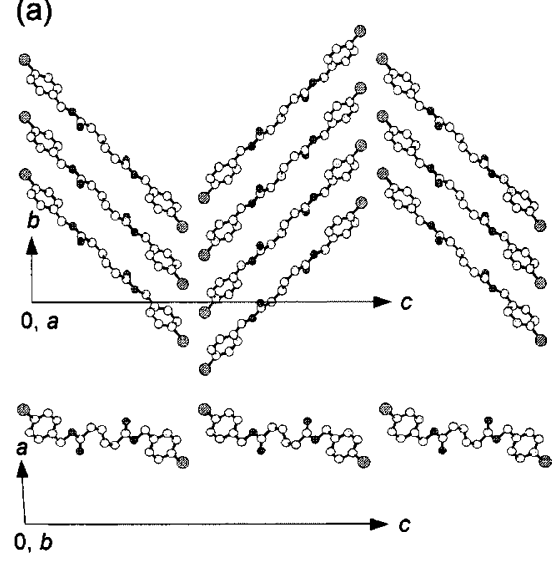

(b)

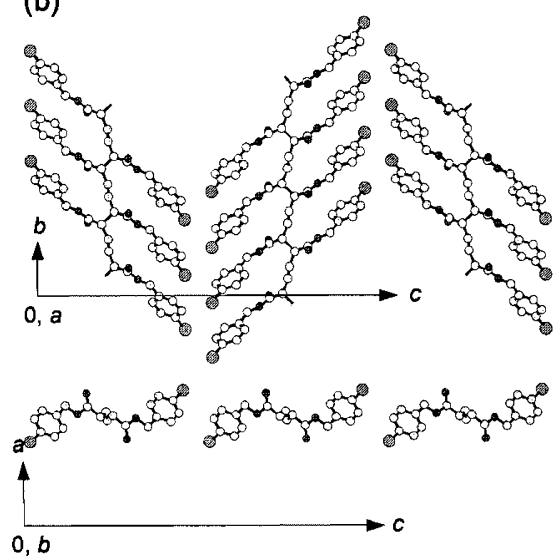

(c)
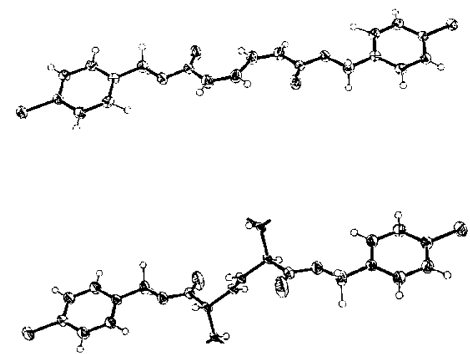

Figure 2. Crystal structures of (a) 1c and (b) poly(1c) viewed down along the crystallographic $a$ - and $b$-axes at the top and bottom, respectively. Hydrogen atoms are omitted for clarity. (c) ORTEP drawing for $1 \mathbf{c}\left(-120^{\circ} \mathrm{C}\right)$ and repeating unit of poly $(\mathbf{1 c})$. Thermal ellipsoids are plotted at the $50 \%$ probability level.

molecular weight polymer is produced independent of the polymerization temperature. This suggests another type of initiation in addition to the photochemical initiation. A strain accumulated in the monomer crystals may initiate new propagation along with the polymer formation. We confirmed that the overall activation energy for the thermal polymerization in the dark is much greater than that for the photopolymerization. For the thermally- and photo-induced polymerization, a similar heterogeneous reaction is involved as the propagation process, but the initiation steps are different from each other. During the photo-induced polymerization, a unimolecular initiation is caused by excitation of the diene part, and a bimolecular initiation is also possibly included due to the crystal-lattice strain. The thermally-induced polymerization contains only a bimolecular coupling as the initiation step for producing two free radicals.

Because the molecular arrangement of monomers determines polymerization reactivity in the crystalline state, crystal structure analysis is a key to understanding the nature of the topochemical polymerization and designing the structure of polymerizable monomer crystals. However, the determination of the single crystal structure of 1a was not easy using a four-circle diffractometer or an imaging plate (IP) system because the polymerization proceeded during the X-ray irradiation before collecting the reflections necessary for the analysis. ${ }^{63}$ Tashiro et al. ${ }^{67}$ successfully determined the crystal structure of 1a using a charged coupled device (CCD) camera system, which can quickly collect the $X$-ray diffraction data with a sufficient quantitative intensity. For the 1a monomer crystal, the 5260 reflections were collected within the first 13 min of the measurement for the structure analysis. A single crystal of poly(1a) was obtained with less strain and fewer de- fects by the X-and $\gamma$-ray radiation polymerizations of the single crystal of 1a. The crystallographic parameters of $1 \mathbf{a}$ and poly(1a) are very similar to each other.

The reflection from the crystals of the polymerizable monomers, 1c and 1d, was also successfully collected using a CCD camera system within a very short time. Figure 2 shows the crystal structures of $1 c$ and poly(1c) ${ }^{42}$ The collection of the reflection data from the monomer crystal was carried out within $10 \mathrm{~min}$ to avoid the effect of the polymerization. Crystals of both the monomer and polymer have identical space groups and similar cell parameters; monoclinic, $P 2_{1} / c$, $a=5.629(6) \AA, b=5.122(6) \AA, c=32.08(2) \AA, \beta=$ 93.712(1) $, V=923.0(4) \AA^{3}, Z=2$ for the $1 \mathrm{c}$ crystal, and monoclinic, $P 2_{1} / c, a=5.6796(3) \AA, b=$ 4.8631(1) $\AA, c=32.097(1) \AA, \beta=90.185(2)^{\circ}, V=$ $886.54(5) \AA^{3}, Z=2$ for the poly(1c) crystal. The same space group before and after the polymerization indicated that this polymerization is really a topochemical polymerization. Here, the number in parentheses indicates the standard deviation of the last digit. The reflection from the monomer crystals observed at room temperature was somewhat insufficient for the least squares refinement. We could successfully collect enough reflections at $-120^{\circ} \mathrm{C}$ without the effect of structural change using an IP detector, due to the suppressed polymerization. The crystal structure at a low temperature agreed well with that at room temperature except for a slight change in the lattice parameters dependent on the temperature; $a=5.6457(2) \AA, b=5.0639(3) \AA$, $c=31.685(4) \AA, \beta=92.746(4)^{\circ}, V=904.82(8) \AA^{3}$ at $-120^{\circ} \mathrm{C}$.

The successful determination of the crystal structure for the monomer and the polymer provides direct and reliable evidence for the topochemical polymerization process and the meso-diisotactic-trans-2,5-structure of 
the polymer. In the monomer crystals, the monomer molecules stack along the $a$ and $b$ axes in a column structure. A polymer chain is produced along the $b$ axis from the consideration of the overlap of the $\pi$-orbitals of the reacting moieties, being in good agreement with the polymer crystal structure. The 4-chlorobenzyl moiety as the side chain has no significant change in its orientation during the polymerization. The polymerization proceeds with only rotation of the diene moiety and with no large movement of the center of mass. The topochemical polymerization of $\mathbf{1 c}$ proceeds accompanying a change in the type of chemical bond with a minimum movement of atoms to produce a polymer chain in the crystals.

Furthermore, we found that $\operatorname{poly}(\mathbf{1 c})$ and $\operatorname{poly}(\mathbf{1 d})$ reversibly change their crystal structure on heating in the solid state. They showed crystal-to-crystal phase transitions below their melting points, 296 and $305^{\circ} \mathrm{C}$ for $\operatorname{poly}(\mathbf{1 c})$ and poly(1d), respectively. This thermal behavior is different from any structural change in common crystalline polymers or the crystals of small organic molecules. Here, crystalline polymers are not identical to polymer crystals in this context, because the former consists of both crystallized and noncrystallized parts. In the polymer crystals prepared by topochemical polymerization, polymer chains are regularly arranged along a specific crystal axis in an expanded chain conformation without containing any amorphous part. In general, polymer single crystals obtained from a dilute solution include lamella structures consisting of folded chains and the crystal size is considerably small, as seen in the single crystals of flexible polyethylene chains. Very recently, Nakamoto et al. have reported the physical and mechanical properties of a giant-scale polymer crystal consisting of a fully extended chain structure, which is uniquely produced by the topochemical polymerization. ${ }^{68}$

\section{TOPOCHEMICAL POLYMERIZATION PRINCIPLES (THE 5 Å RULE)}

Crystal engineering is the planning of the properties and functions of crystalline materials using preorganized molecules. ${ }^{58,61}$ This process involves the control of crystal packing on the basis of information from the chemical structure of the molecules and is required for clarification of the correlation between the structure and functions. It has been recognized for a long time that the prediction and rational design of crystal structures are not easy, as was already described. Nevertheless, we started to investigate the molecular packing in the crystals of many diene monomers that can or cannot undergo topochemical polymerization, (a)

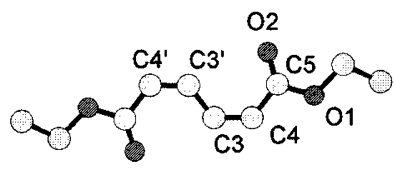

(b)

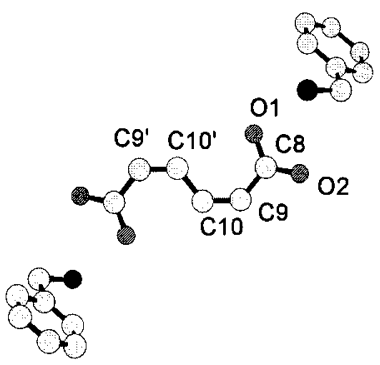

(c)

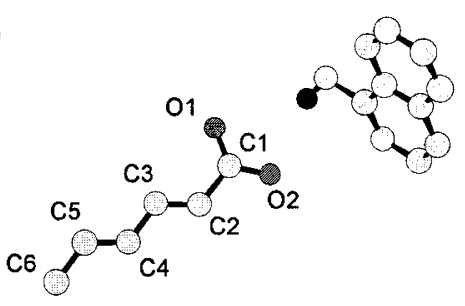

Figure 3. Planar molecular conformations of 1,3-diene monomers determined by single crystal structure analysis. (a) $\mathrm{C}(3)-\mathrm{C}(4)-\mathrm{C}(5)-\mathrm{O}(1)=179.1(3)^{\circ}, \quad \mathrm{C}(3)-\mathrm{C}(4)-\mathrm{C}(5)-\mathrm{O}(2)=$ $1.3(3)^{\circ}, \quad \mathrm{C}\left(3^{\prime}\right)-\mathrm{C}(3)-\mathrm{C}(4)-\mathrm{C}(5)=0.0(2)^{\circ}, \quad \mathrm{C}\left(4^{\prime}\right)-\mathrm{C}\left(3^{\prime}\right)-\mathrm{C}(3)-$ $\mathrm{C}(4)=180^{\circ}$ for the muconic ester, 1a. (b) $\mathrm{C}(10)-\mathrm{C}(9)-\mathrm{C}(8)-\mathrm{O}(1)=$ $17.6(7)^{\circ}, \quad \mathrm{C}(10)-\mathrm{C}(9)-\mathrm{C}(8)-\mathrm{O}(2)=-162.4(5)^{\circ}, \mathrm{C}\left(10^{\prime}\right)-\mathrm{C}(10)-$ $\mathrm{C}(9)-\mathrm{C}(8)=-3.4(9)^{\circ}, \mathrm{C}\left(9^{\prime}\right)-\mathrm{C}\left(10^{\prime}\right)-\mathrm{C}(10)-\mathrm{C}(9)=180^{\circ}$ for the ammonium muconate, 2f. (c) $\mathrm{C}(3)-\mathrm{C}(2)-\mathrm{C}(1)-\mathrm{O}(1)=178.6(8)^{\circ}$, $\mathrm{C}(3)-\mathrm{C}(2)-\mathrm{C}(1)-\mathrm{O}(2)=-1.7(1)^{\circ}, \quad \mathrm{C}(4)-\mathrm{C}(3)-\mathrm{C}(2)-\mathrm{C}(1)=$ $-179.3(6)^{\circ}, \mathrm{C}(5)-\mathrm{C}(4)-\mathrm{C}(3)-\mathrm{C}(2)=-179.3(7)^{\circ}, \mathrm{C}(6)-\mathrm{C}(5)-\mathrm{C}(4)-$ $C(3)=-179.0(6)^{\circ}$ for the ammonium sorbate, $\mathbf{5 c}$.

in order to understand the crystal structure and polymerization reactivity relationship. We also examined the role of strong and weak intermolecular interactions such as hydrogen bonds as well as $\mathrm{CH} / \pi, \mathrm{CH} / \mathrm{O}$, and halogen-halogen interactions to clarify the factors controlling the crystal structures and the reactivity in the solid state, as shown in the next section.

The muconic and sorbic acid derivatives with $Z Z$ and $E E$-configurations have similar molecular conformations in the crystalline state. All the diene monomers favor an s-trans conformation with a highly planar structure (Figure 3). The torsion angles indicate the highly planar structure of a diene moiety for each monomer. The carbonyl group protrudes from the diene plane for the ammonium derivatives due to the two-dimensional (2D) hydrogen bond network formation between the carboxylate and ammonium groups. These torsion angles indicate that the stacking style of the ammonium sorbates is fitted with 2D hydrogen bond networks compared with that of the ammonium muconates. This is because both ends of the mu- 
Table II. Monomer stacking parameters for the crystals of topochemically polymerizable 1,3-diene mono- and dicarboxylic acid derivatives $^{\mathrm{a}}$

\begin{tabular}{|c|c|c|c|c|c|c|c|c|}
\hline $\begin{array}{l}\text { Mono- } \\
\text { mer }\end{array}$ & $\begin{array}{l}O \text { - and } N- \\
\text { Substituent }\end{array}$ & $\begin{array}{l}\text { Space } \\
\text { group }\end{array}$ & $\frac{\text { Temp. }}{{ }^{\circ} \mathrm{C}}$ & $\frac{d_{\mathrm{s}}}{\AA}$ & $\frac{d_{\mathrm{cc}}}{\AA}$ & $\frac{\theta_{1}}{\text { degree }}$ & $\frac{\theta_{2}}{\text { degree }}$ & ref $^{b}$ \\
\hline $1 \mathbf{a}-\mathrm{I}$ & ethyl & $P 2_{1} / c$ & 25 & $4.9310(6)$ & 3.79 & 79 & 49 & 67 \\
\hline $1 \mathrm{c}$ & 4-chlorobenzyl & $P 2_{1} / c$ & 25 & $5.122(6)$ & 3.56 & 82 & 44 & 42 \\
\hline $1 \mathrm{c}$ & 4-chlorobenzyl & $P 2_{1} / c$ & -120 & $5.0639(3)$ & 3.48 & 78 & 43 & 42 \\
\hline 1d-I & 4-bromobenzyl & $P 2_{1} / c$ & 25 & $5.21(1)$ & 3.89 & 72 & 49 & 42 \\
\hline 1e & 4-methoxybenzyl & $C 2 / c$ & -70 & $9.4840(7)^{\mathrm{c}}$ & 3.44 & d & d & 43 \\
\hline $2 f$ & benzyl & $P 2_{1} / a$ & -63 & $4.862(2)$ & 4.24 & 67 & 55 & 46 \\
\hline $2 \mathrm{~g}$ & 2-chlorobenzyl & $P 2_{1} / a$ & 23 & $4.9360(8)$ & 4.19 & 62 & 52 & 46 \\
\hline 3a & 4-methoxybenzyl & $C 2 / c$ & -70 & $9.7803(6)^{\mathrm{c}}$ & 3.32 & d & d & 43 \\
\hline $5 \mathbf{b}$ & 2-methylbenzyl & $P 2_{1} / a$ & 23 & $4.9958(8)$ & 5.35 & 28 & 60 & 85 \\
\hline $5 \mathbf{a}$ & 4-methylbenzyl & $P \overline{1}$ & 23 & $4.932(1)$ & 5.43 & 24 & 61 & 85 \\
\hline $5 \mathrm{c}$ & 1-naphthylmethyl & $C 2 / c$ & 23 & $4.9909(1)$ & 5.35 & 29 & 61 & 48 \\
\hline $6 a$ & $p$-xylylene & $P \overline{1}$ & 23 & $4.9876(5)$ & 5.47 & 25 & 60 & 130 \\
\hline $8 \mathbf{a}$ & $\mathrm{Li}$ & $C 2 / c$ & 21 & $5.037(2)$ & 5.69 & 7 & 32 & 52 \\
\hline 9a & 1-naphthylmethyl & $\mathrm{Pca2}_{1}$ & -70 & $4.9472(5)$ & 5.31 & 29 & 61 & 50 \\
\hline $9 \mathrm{~b}$ & 1-naphthylmethyl & $C 2 / c$ & 23 & $4.9006(5)$ & 3.30 & 87 & 42 & 50 \\
\hline
\end{tabular}

${ }^{\mathrm{a}} d_{\mathrm{cc}}$ : distance between the reacting $\mathrm{C}_{2}$ and $\mathrm{C}_{5}^{\prime}$ carbons, $d_{\mathrm{s}}$ : stacking distance, $\theta_{1}, \theta_{2}$ : tilt angles of the molecular plane. ${ }^{\mathrm{b}}$ References to X-ray single crystal structure. ${ }^{\mathrm{c}}$ Twice of $d_{\mathrm{s}}$ values due to the alternate molecular stacking in a column (see text). ${ }^{\mathrm{d}}$ Not determined.

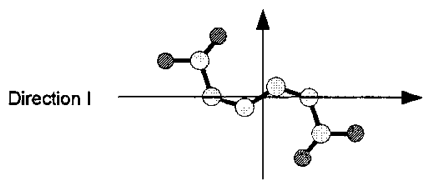

Direction if

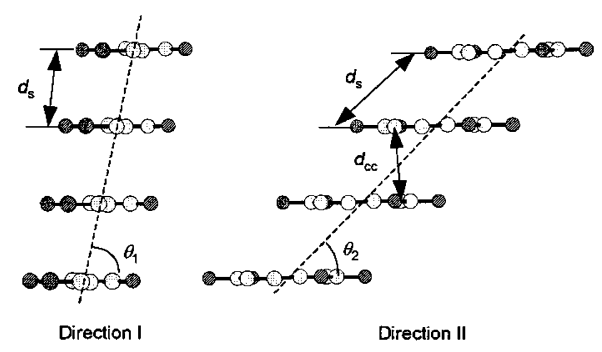

Figure 4. Stacking model for the muconate derivatives in the crystalline state and the definition of stacking parameters used for the prediction of the topochemical polymerization reactivity. $d_{\mathrm{cc}}$ is the intermolecular distance between the 2- and 5'-carbons. $d_{\mathrm{s}}$ is the stacking distance between the adjacent monomers in a column. $\theta_{1}$ and $\theta_{2}$ are the angles between the stacking direction and the molecular plane in orthogonally different directions. The view from direction I is parallel to a vector through the 2- and 5-carbons of the diene moieties.

conate dianions are linked to the $2 \mathrm{D}$ networks and a consequently considerable intramolecular distortion is caused. They also show that the muconic esters have no intramolecular torsion because of no strong intermolecular interactions.

The stacking structure of the monomers is evaluated using the following parameters: ${ }^{50}$ the intermolecular distance between carbons that react to form a new bond during the topochemical polymerization $\left(d_{\mathrm{cc}}\right)$, the stacking distance along the column $\left(d_{\mathrm{s}}\right)$, and the angles between the stacking direction and the molecular plane in orthogonally different directions $\left(\theta_{1}\right.$ and $\left.\theta_{2}\right)$. The definition is shown in Figure 4. The values of the parameters determined are summarized in Table II and III for various kinds of topochemically polymerizable and non-polymerizable monomers, respectively.

The polymerizable monomer crystals exhibit $d_{\mathrm{cc}}$ values over a relatively wide range of 3.3-5.7 $\AA$, and this increases in the order of monomer species $\mathbf{3} \leq \mathbf{1}<\mathbf{2}$ $<\mathbf{5} \simeq \mathbf{6}$. The $\theta_{1}$ and $\theta_{2}$ values are also dependent on the monomer structure. The $\theta_{1}$ values for the ammonium sorbates $\left(\theta_{1}=24-29^{\circ}\right)$ are much smaller than those for the salts $\left(\theta_{1}=62-67^{\circ}\right)$ and esters $\left(\theta_{1}=72-\right.$ $82^{\circ}$ ) of muconates. This indicates that the diene plane of the sorbates leans in a polymerizable direction in the column. This offset stacking includes a structure that has an unfavorable overlap of the $\pi$-orbitals. However, because the sorbate anions are fixed on the sheet of the hydrogen bond network only at one side, the diene parts of the sorbates can twist and revolve easily to change molecular conformation suitable for the polymerization. The $\theta_{2}$ values for the polymerizable sorbates are greater than those of the muconates. This suggests that the intramolecular torsion angles between the conjugated $\pi$-plane and the carboxylate are related to the close packing of planar molecules on the hydrogen bond networks appropriate for the polymerization.

In contrast, all the $d_{\mathrm{s}}$ values are in an exclusively limited region of 4.74-5.21 $\AA$. The average $d_{\mathrm{s}}$ value is $4.97 \pm 0.11 \AA$ for the polymerizable monomers. Figure 5 shows the relationship between the $d_{\mathrm{s}}$ and $\theta_{2}$ val- 
Table III. Monomer stacking parameters for the crystals of topochemically non-polymerizable 1,3-diene mono- and dicarboxylic acid derivatives ${ }^{\mathrm{a}}$

\begin{tabular}{|c|c|c|c|c|c|c|c|c|}
\hline $\begin{array}{l}\text { Mono- } \\
\text { mer }\end{array}$ & $\begin{array}{l}O \text { - and } N \text { - } \\
\text { Substituent }\end{array}$ & $\begin{array}{l}\text { Space } \\
\text { group }\end{array}$ & $\frac{\text { Temp. }}{{ }^{\circ} \mathrm{C}}$ & $\frac{d_{\mathrm{s}}}{\AA}$ & $\frac{d_{\mathrm{cc}}}{\AA}$ & $\frac{\theta_{1}}{\text { degree }}$ & $\frac{\theta_{2}}{\text { degree }}$ & $\mathrm{ref}^{\mathrm{b}}$ \\
\hline 1a-II & ethyl & $P 2_{1} / c$ & -80 & $4.253(3)$ & 3.88 & 80 & 57 & 60 \\
\hline 1f $-\mathrm{I}$ & benzyl & $P 2_{1} / c$ & 25 & $5.6900(10)$ & 6.42 & 12 & 61 & 70 \\
\hline 1f-II & benzyl & $P 2_{1} / c$ & 25 & $9.368(4)$ & 6.14 & 52 & 19 & 42 \\
\hline $1 \mathrm{~g}$ & 3-chlorobenzyl & $P \overline{1}$ & 23 & $4.0436(5)$ & 4.35 & 67 & 67 & 42 \\
\hline $1 \mathrm{~h}$ & 4-fluorobenzyl & $P 2_{1} / c$ & 23 & $4.112(6)$ & 5.17 & 66 & 82 & 42 \\
\hline 1d-II & 4-bromobenzyl & $P 2_{1} / n$ & 23 & $8.049(1)$ & 5.01 & 62 & 24 & 42 \\
\hline $\mathbf{1 i}$ & 4-methylbenzyl & $P \overline{1}$ & 23 & $11.7151(7)$ & 8.55 & 49 & 19 & 42 \\
\hline $\mathbf{1 j}$ & 2-chloroethyl & $P 2_{1} / a$ & -70 & $5.4164(3)$ & 4.92 & 16 & 26 & 42 \\
\hline $1 \mathrm{k}$ & 2-bromoethyl & $P 2_{1} / a$ & 23 & $5.5002(7)$ & 5.00 & 17 & 27 & 42 \\
\hline 11 & 2,2,2-trichloroethyl & $P 2_{1} 2_{1} 2_{1}$ & 23 & $5.860(4)$ & 4.02 & 68 & 40 & 70 \\
\hline $1 \mathrm{~m}$ & methyl & $P \overline{1}$ & 23 & $5.788(7)$ & 3.79 & 72 & 39 & 70 \\
\hline \multirow[t]{2}{*}{ 1n } & decyl & $P \overline{1}$ & 23 & $5.498(7)$ & 3.69 & 70 & 40 & 70 \\
\hline & & & & $5.486(14)$ & 3.69 & 48 & 36 & 70 \\
\hline \multirow[t]{2}{*}{10} & cyclohexyl & $P \overline{1}$ & 23 & $6.3670(27)$ & 5.20 & 57 & 25 & 70 \\
\hline & & & & $6.93^{\mathrm{c}}$ & 5.20 & 32 & 28 & 70 \\
\hline 2l & 3-methylbenzyl & $P 2_{1} / a$ & 23 & $8.614(2)$ & 8.38 & 19 & 49 & 46 \\
\hline $2 \mathrm{~m}$ & 2-methoxybenzyl & $P 2_{1} / a$ & 23 & $8.5940(6)$ & 8.33 & 20 & 49 & 46 \\
\hline $2 n$ & 4-methoxybenzyl & $P \overline{1}$ & 23 & $5.599(3)$ & 4.79 & 3 & 5 & 46 \\
\hline 20 & 3,4-dichlorobenzyl & $P 2_{1} / a$ & 23 & $8.842(1)$ & 8.53 & 19 & 46 & 46 \\
\hline $2 p$ & $\alpha$-methylbenzyl & $C 2$ & -76 & $6.139(2)$ & 5.21 & 13 & 19 & 46 \\
\hline $3 b-I$ & benzyl & $P 2_{1} / c$ & 23 & $5.706(6)$ & 5.91 & 6 & 20 & 42 \\
\hline $3 b-I I$ & benzyl & $P 2_{1} 2_{1} 2_{1}$ & 23 & $5.766(2)$ & 5.88 & 6 & 20 & 42 \\
\hline $3 c$ & 2-chlorobenzyl & $P 2_{1} / n$ & 23 & $6.015(4)$ & 4.22 & 58 & 39 & 42 \\
\hline 3d & 3-chlorobenzyl & $P 2_{1} / c$ & 23 & $9.373(2)$ & 5.99 & 83 & 18 & 42 \\
\hline $3 e$ & 4-bromobenzyl & $P 2_{1} / c$ & 23 & $5.6741(8)$ & 5.98 & 1 & 4 & 42 \\
\hline $3 f$ & 2,2,2-trichloroethyl & $P 2_{1} / c$ & 23 & $6.067(30)$ & 4.51 & 41 & 36 & 70 \\
\hline $3 g$ & methyl & $P \overline{1}$ & 23 & $5.810(8)$ & 3.55 & 63 & 33 & 70 \\
\hline $3 \mathbf{h}$ & ethyl & $P 2_{1} / c$ & 23 & $7.849(13)$ & 5.44 & 45 & 29 & 70 \\
\hline $3 \mathbf{i}$ & cyclohexy & $P \overline{1}$ & 23 & $9.37^{\mathrm{c}}$ & 6.76 & 76 & 25 & 70 \\
\hline $5 d$ & benzyl & $P 2_{1} / n$ & 23 & 6.3834 & 4.00 & 42 & 26 & 85 \\
\hline $5 e$ & 2-methoxybenzyl & $P \overline{1}$ & 23 & $5.9425(12)$ & 6.87 & 10 & 78 & 85 \\
\hline $5 f$ & 3-methoxybenzyl & $P 2_{1} / c$ & 23 & $5.51^{\mathrm{c}}$ & 6.07 & 8 & 36 & 85 \\
\hline $5 \mathrm{~g}$ & 4-chlorobenzyl & $P \overline{1}$ & -70 & $5.6943(9)$ & 6.86 & 9 & 72 & 85 \\
\hline $5 \mathbf{h}-\mathrm{I}$ & $\alpha$-methylbenzyl & $P \overline{1}$ & -70 & $10.3012(6)$ & 7.13 & 65 & 22 & 85 \\
\hline $5 \mathbf{h}-\mathrm{II}$ & $\alpha$-methylbenzyl & $P \overline{1}$ & 23 & $5.8698(1)$ & 6.62 & 3 & 31 & 85 \\
\hline $5 \mathbf{i}$ & indenyl & $P \overline{1}$ & 23 & $5.7056(6)$ & 6.26 & 5 & 29 & 85 \\
\hline $5 \mathbf{j}$ & $(S R)$-(1-naphthyl)ethyl & $C 2 / c$ & 23 & $4.57^{\mathrm{c}}$ & 5.45 & 40 & 78 & 85 \\
\hline $5 \mathbf{k}$ & $(S)$-(1-naphthyl)ethyl & $P 2_{1}$ & 23 & $5.4874(3)$ & 6.32 & 9 & 58 & 85 \\
\hline 51 & $(S)$-(1-cyclohexyl)ethyl & $P 2{ }_{1} 2_{1} 2_{1}$ & 23 & $5.6624(5)$ & 6.43 & 6 & 48 & 85 \\
\hline $5 \mathrm{~m}$ & sec-butyl & $P 2_{1} / n$ & 23 & $6.4642(7)$ & 3.83 & 14 & 8 & 85 \\
\hline $5 n$ & tert-butyl & $P \overline{1}$ & 23 & $6.642(3)$ & 3.94 & 7 & 4 & 85 \\
\hline
\end{tabular}

${ }^{\mathrm{a}} d_{\mathrm{cc}}$ : distance between the reacting $\mathrm{C}_{2}$ and $\mathrm{C}_{5}^{\prime}$ carbons, $d_{\mathrm{s}}$ : stacking distance, $\theta_{1}, \theta_{2}$ : tilt angles of the molecular plane. ${ }^{b}$ References to X-ray single crystal structure. ${ }^{c}$ Not parallel to an axis.

ues. The curve drawn in this figure is calculated for the closest packing of the planar molecules with a thickness of $3.5 \AA$ and a $\theta_{1}$ value of $90^{\circ}$. For the muconic ester monomers $\mathbf{1}$ and $\mathbf{3}$, the plots are situated near the calculated curve because of the closest packing of the planar molecules in the crystals. The ammonium derivatives often favor various structures, not a columnar structure, resulting in the scattered plots far from the calculated curve. This is due to the diversity in the hydrogen bond pattern including one-dimensional (1D) ladders and 2D sheets, depending on the structure of the $N$-substituted groups. The isomerism of the hydrogen bond network structure often prevents us from predicting reactivity from the molecular structures. Therefore, we have revealed factors for controlling the hydrogen bond networks for the crystals of ammonium salts of muconic and sorbic acids (see the next section).

In Table III, several monomers have shorter $d_{\mathrm{cc}}$ and 


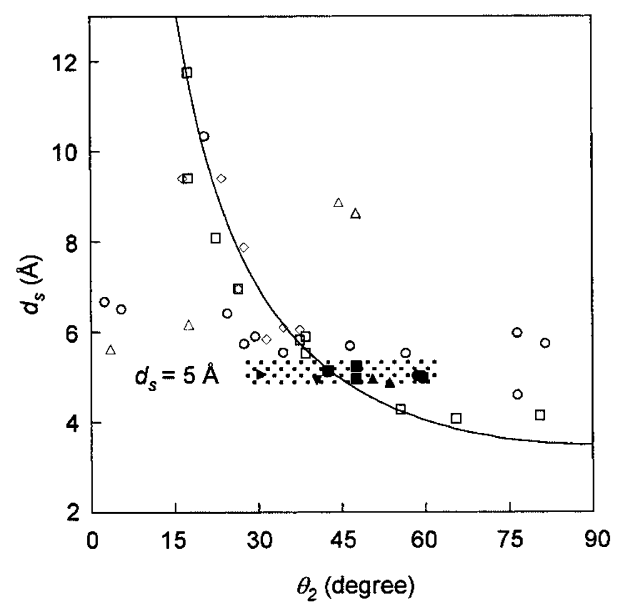

Figure 5. Relationship between the $d_{\mathrm{s}}$ and $\theta_{2}$ values for the 1,3diene monomers in the crystals. ( $\square) \mathbf{1},(\triangle) \mathbf{2},(\diamond) \mathbf{3},(\mathrm{O}) 5$ including 6a, ( $\mathbf{\nabla})$ 9, ( $\bullet$ ) 8a (ref 52). Closed and open symbols represent polymerizable and non-polymerizable monomers, respectively. The curve is calculated for the closed packing of planar monomers with a thickness of $3.5 \AA$ and $\theta_{1}$ of $90^{\circ}$.

$d_{\mathrm{s}}$ values, and they are actually non-polymerizable although this appears to be advantageous for the polymerization. For example, 1a has an alternative crystal structure at a low temperature due to the first-order phase transition, which seriously affects the polymerization reactivity. 1a polymerizes quite rapidly at room temperature, but not at all below $-45^{\circ} \mathrm{C}$. The stacking parameters were determined at a low temperature by Saragai et al. $.^{69} d_{\mathrm{cc}}=3.88 \AA, d_{\mathrm{s}}=4.25 \AA, \theta_{1}=80^{\circ}$, and $\theta_{2}=57^{\circ}$, which are very similar to those for the polymerizable structure at room temperature: $d_{\mathrm{cc}}=3.79 \AA$, $d_{\mathrm{S}}=4.93 \AA, \theta_{1}=79^{\circ}$, and $\theta_{2}=49^{\circ}$. In this way, a slight change in the $d_{\mathrm{s}}$ value from $4.93 \AA$ to $4.25 \AA$ or a deviation from the limited zone appropriate for the polymerization in Figure 5 diminishes the polymerization reactivity of 1a. We emphasize the importance of the $d_{\mathrm{s}}$ value for the topochemical polymerization process. The stacking distances of the polymerizable monomers are close to the values of the repeating unit, i.e., a fiber period of polymer chains with a fully stretched conformation, produced along with a crystallographic axis in the crystals. The fiber period for $\operatorname{poly}(\mathbf{1 a})$ and $\operatorname{poly}(\mathbf{1 c})$ was experimentally determined to be $4.84 \AA$ from the $\mathrm{X}$-ray diffraction of the polymer single crystals. ${ }^{42,67}$ If the polymerization proceeds for $d_{\mathrm{S}}$ values greater or smaller than $5 \AA$, then monomer molecules have to translate along the stacking axis during the polymerization. When the $d_{\mathrm{s}}$ value is close to the fiber period of the resulting polymer, monomer molecules rotate with the minimum translational movement and form a bond between the 2- and $5^{\prime}$-carbon atoms.

Several halogen-substituted benzyl esters of $(Z, Z)$ muconic acid ( $\mathbf{~} \mathbf{g}$ and $\mathbf{1} \mathbf{~ h}$ ) have a smaller $d_{\mathrm{s}}$ value (4.04

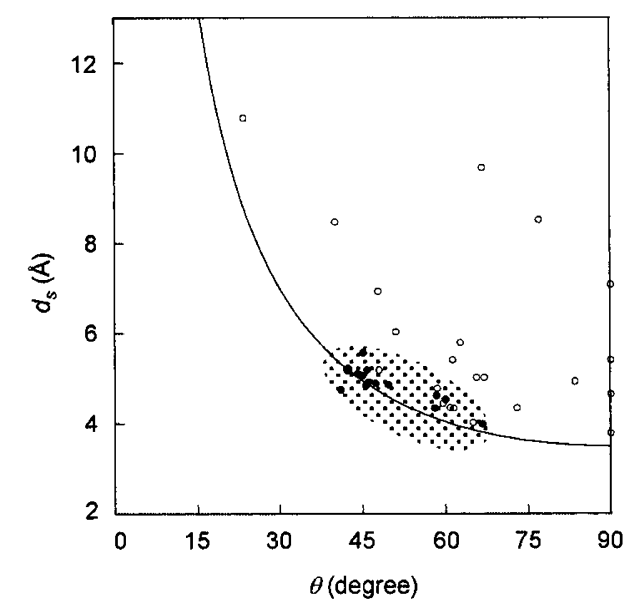

Figure 6. Relationship between the $d_{\mathrm{s}}$ and $\theta$ values for the 1,3diacetylenes in the crystals. Closed and open symbols represent polymerizable and non-polymerizable monomers, respectively.

and $4.11 \AA$, respectively) than the unsubstituted (1f) or methyl-substituted benzyl (1i) esters. This suggests that the ester monomer molecules can be more closely assembled by the introduction of a halogen atom on the phenyl ring. When the $\theta_{2}$ value is closer to $90^{\circ}$, there is a possibility for zigzag-type polymerization, which progresses with alternating $\mathrm{C}_{2}-\mathrm{C}_{2}^{\prime}$ and $\mathrm{C}_{4}-\mathrm{C}_{4}^{\prime}$ reaction. However, we observed no evidence of the polymerization of $\mathbf{1 ~ g}$ and $\mathbf{1 ~ h}$ during the photoirradiation. It is impossible to form a new carbon-to-carbon bond during the photoirradiation only by rotation of the diene moiety without any translational movement in the crystals when the $d_{\mathrm{s}}$ value is shorter than the ideal one. The zigzag-type polymerization hardly occurs for the 1,3-diene monomers, although such a possibility was postulated for the diacetylene and diolefin polymerizations. $^{71,72}$

The present polymerization principles for the 1,3diene monomers seem to have features similar to the empirical rules for the polymerization of diacetylene compounds reported in the literature; ${ }^{24,25} d_{\mathrm{s}} \simeq 5 \AA$ and $\theta \simeq 45^{\circ}$. However, the former rules are more sensitive to a slight change in the monomer crystal structure. In other words, the tolerable range in the $d_{\text {s }}$ values is very narrow for the polymerizable 1,3diene monomers, and the regions for the polymerizable and non-polymerizable monomers are clearly divided in Figure 5. In contrast, the plots for polymerizable and non-polymerizable monomers are mingled even in an ideal zone around a $d_{\mathrm{s}}$ value of $5 \AA$ and a $\theta$ value of $45^{\circ}$ in the relationship between the $d_{\mathrm{s}}$ and $\theta$ values for diacetylenes (Figure 6), which is plotted based on the structural data reported in the review in 1984 by Emkelmann. ${ }^{25}$ This is due to the differences in the planar and linear molecular shapes of dienes and 

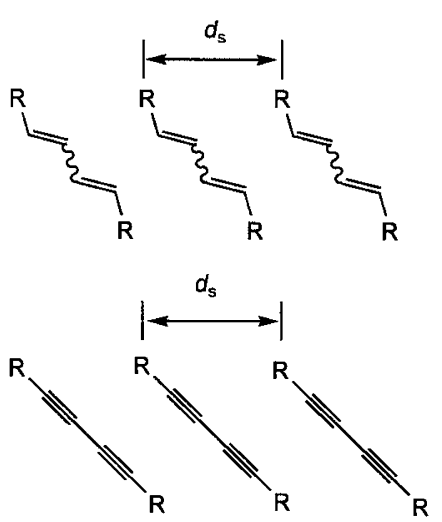
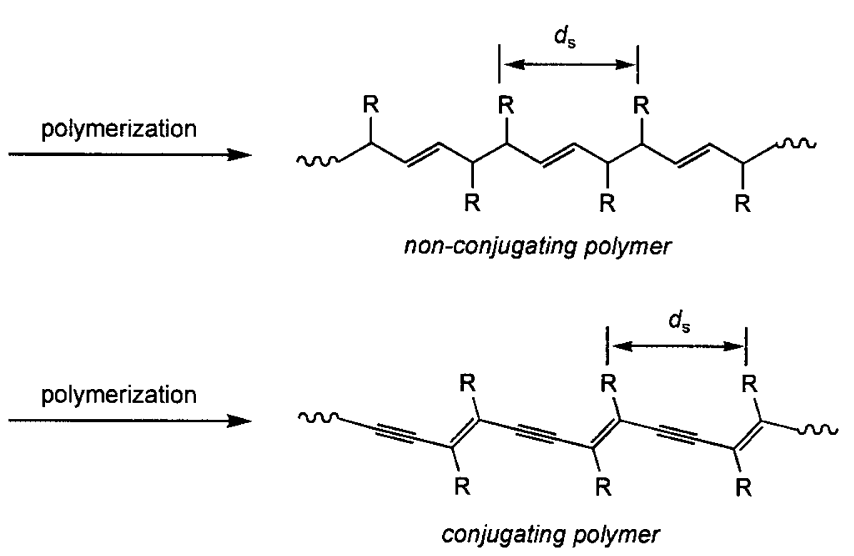

Scheme 3.

diacetylenes, respectively, that is, the direction of the $\pi$-orbital of the reacting moieties. Because the structural factors of diene polymerization in the crystalline state are not as straightforward as those for diacetylene polymerization, the discovery and generalization of diene polymerization in the crystalline state has greatly lagged behind. It is also noteworthy that polymorphism is important as another factor for the acetylene polymerization relationship. Regarding the literature values of crystal structures, the conditions for crystallization (for example, temperature, solvents, etc.) are not always the same for the structure determination and the polymerization test because of some limits in the conditions for single crystal structure analysis with a classic apparatus such as a four-circle diffractometer for several days at a low temperature in the 1970 s to 80 s. The experimental conditions are required to be the same, as much as possible, for the crystal fabrication and handling during both the X-ray crystal structure analysis and the topochemical polymerization experiments.

Currently, in any case, topochemical polymerization is opened not only to the diacetylene library but also to the diene library that is more popular and a larger collection. The $5 \AA$ rule in this work is a first step in the rational design for the topochemical polymerization of diene monomers, moving away from the trial-and-error approach. Diene polymerization has the potential of being applied to the construction of advanced organic materials in the solid state, because the topochemical polymerization of diacetylene and diene monomers provides different types of polymers, that is, conjugate and non-conjugate polymers, respectively (Scheme 3 ). The combination of these different polymers would be used as molecular devices for optics and optoelectronics in future.

\section{CRYSTAL STRUCTURE DESIGN}

The next question is how to create a suitable stacking distance of $5 \AA$ for the polymerization in the crystals of the diene monomers. Some supramolecular synthons ${ }^{73}$ are available for the topochemical polymerization of the 1,3-diene carboxylic acid derivatives; for example, a $2 \mathrm{D}$ hydrogen bond network, ${ }^{74-80}$ aromatic ring stacking, ${ }^{59} \mathrm{CH} / \pi,{ }^{81} \mathrm{CH} / \mathrm{O},{ }^{82-84}$ and halogen-halogen ${ }^{59}$ interactions (Figure 7) ${ }^{50}$ In the $2 \mathrm{D}$ hydrogen bond network formed between primary ammoniums and carboxylates, the ammonium and carboxylate groups act as triple hydrogen bond donors and acceptors, respectively. Regarding the close stacking of aromatic rings, the benzyl and naphthylmethyl moieties are packed in the crystals with a herringbone or $\gamma$-type structure. The $\mathrm{CH} / \pi$ interaction between aromatic and benzyl groups is also important. For the benzyl-, 4-methylbenzyl-, and $p$-xylylenediammonium crystals, the interaction of $\pi$-electrons with the benzylic hydrogens is observed. In the naphthylmethylammonium crystals, both interactions between the $\pi$ and aromatic or benzylic hydrogens are observed. The validity of the halogen-halogen interactions has been proved by the chlorine or bromine atom substitution of the benzyl muconate. It is noteworthy that a naphthylmethylammonium as the countercation is eminent for forming a robust layer structure in which diene carboxylic acid molecules are arranged in a fashion appropriate for the polymerization as a result of the synergetic effects of the $2 \mathrm{D}$ hydrogen bond network, aromatic stacking, and $\mathrm{CH} / \pi$ interaction. Matsumoto and Sada et al. have demonstrated the successful polymerization examples of several kinds of diene carboxylic acids (not only the muconic and sorbic acid derivatives but also the other diene monomers such as 9). ${ }^{50}$ The crystal structure and molecular packing of 

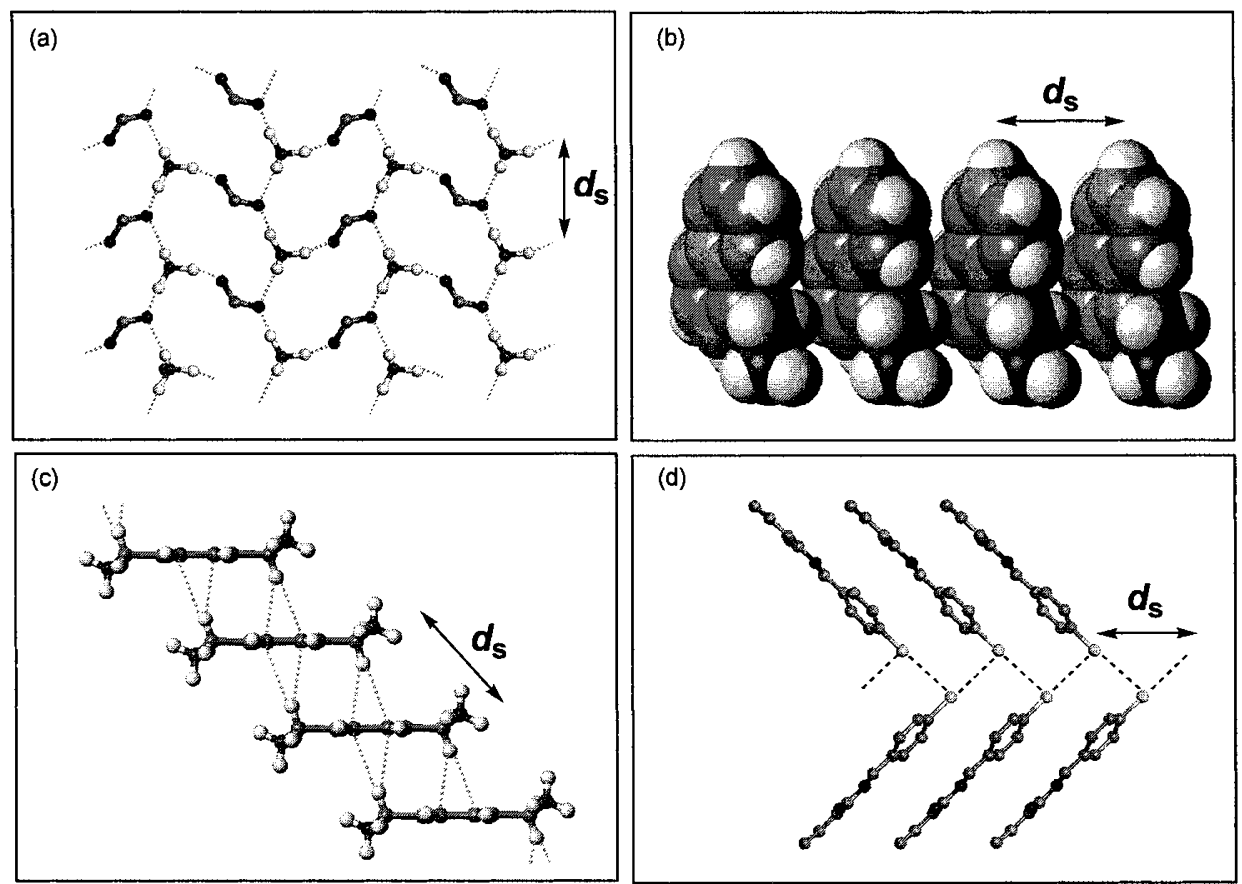

Figure 7. Supramolecular synthons for the molecular stacking with a $5 \AA$ distance. This stacking distance is appropriate for the topochemical polymerization of the 1,3-diene monomers. (a) 2D hydrogen bond network, (b) aromatic ring stacking, (c) $\mathrm{CH} / \pi$ interaction between aromatic and benzyl groups, and (d) halogen-halogen zigzag chains.

9a and 9d are similar to the other polymerizable sorbate and muconate monomers, indicating that the polymerization principles are valid for a variety of diene monomers other than the muconates and sorbates.

For the crystal structure design of the ammonium derivatives using the hydrogen bond network, the diversity and isomerism of hydrogen bond networks are a problem to be overcome. Recently, Nagahama and Inoue et al. reported the control of 2D hydrogen network structures using $\mathrm{CH} / \pi$ interaction. ${ }^{85}$ The $2 \mathrm{D}$ hydrogen bond networks for the polymerizable monomers involve two kinds of the pattern as shown in Figure 8a. The sorbate or muconate anions and the primary ammonium cations are linked to each other through hydrogen bond networks. The primary ammonium cations form hydrogen bonds with three neighboring carboxylate anions, and, in turn, the carboxylate groups with three neighboring ammonium cations. Irrespective of the molecular structure, all of the polymerizable monomers have an identical hydrogen bond network structure; 16membered rings are the repeating units in the $2 \mathrm{D}$ sheet. The 2D hydrogen bond networks run perpendicular to the molecular plane of the dienes and support a suitable columnar structure for topochemical polymerization. They include two types of the arrangements of the columns; one is a parallel arrangement in which all the columns run to the same direction, and another is an anti-parallel arrangement in which they run alternatively to the opposite directions. Here, we notice that the crystals favor an anti-parallel style when the alkyl substituent in the countercation has an asymmetric structure such as 2-methylbenzyl, 2-chlorobenzyl, and 1-naphthylmethyl group. On the other hand, the monomers with a symmetric countercation tend to fall into a parallel-type columnar packing.

The non-polymerizable salts have a variety of hydrogen bond networks. As shown in Figures $8 \mathrm{~b}-8 \mathrm{e}$, they are divided into four categories (types I-IV) for the sorbates, and three (types V-VII) for the muconates, on the basis of unit hydrogen bond cycles and the numbers of the incorporated atoms. The type I is built up of the successive 8-, 12-, 12-, and 12-membered rings. The second one is a repeated 10 -membered ring consisting of four hydrogen, one carbon, three oxygen, and two nitrogen atoms along two-fold screw axis (type II). The other salts have alternate 8- and 12-membered rings (type III), related by an inversion center. Type IV is the hydrogen bond network in the 2D sheet-type, consisting of 12- and 20-membered rings as the repeating units. The types V-VII illustrate the hydrogen bond networks of non-polymerizable muconate derivatives. There are two cases of the 1D ladder structures, one of which is a repeated 10-membered ring, and another has the alternate 8- and 12-membered rings. The 1D ladders are linked to each other by the muconate anions to form a sheet structure. Type VII is the 2D sheettype crystal. The types V-VII for the muconates are basically identical to the types II-IV for the sorbates, respectively.

As discussed earlier, a stacking distance of $5 \AA$ is the 
(a)

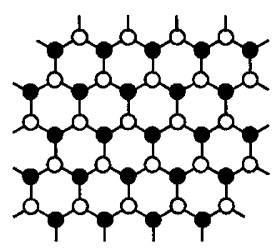

polymerizable $2 \mathrm{D}$ network

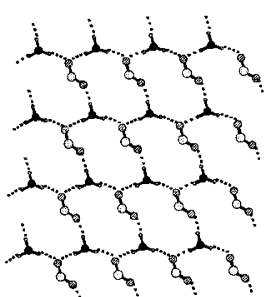

parallel type

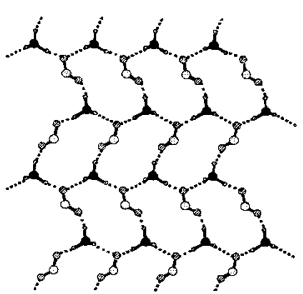

anti-parallel type (b)

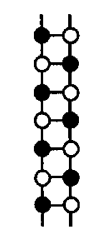

1D ladder

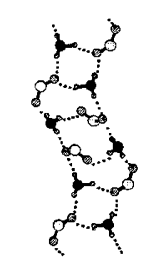

type I

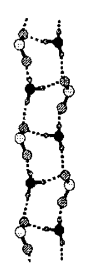

type II

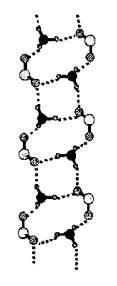

type III (c)

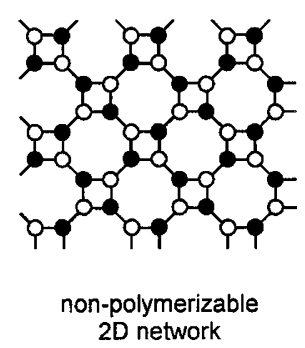

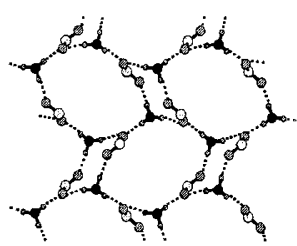

type IV (d)

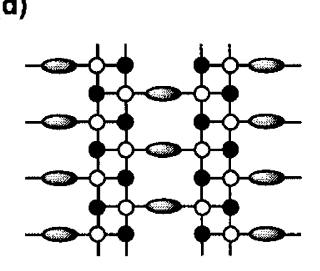

bridged $1 \mathrm{D}$ ladders

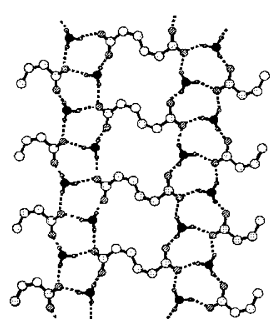

type V

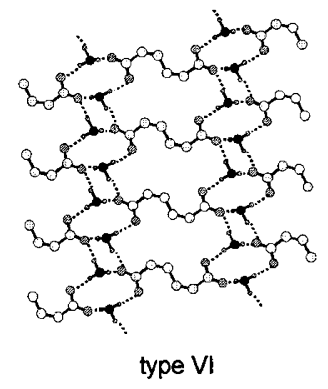

(e)

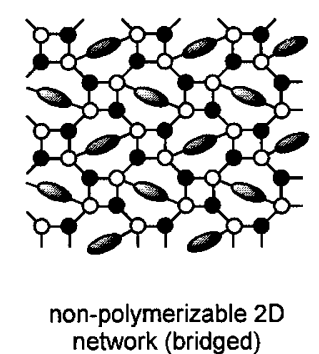

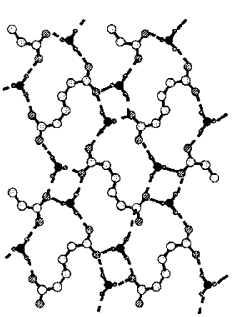

type VII

Figure 8. Classification of the pattern of the hydrogen bond networks. (a) Polymerizable 2D network, (b) 1D ladder, (c) nonpolymerizable 2D network, (d) bridged 1D ladder for the muconates, and (e) bridged 2D network for the muconates. In the schematic models (left), open and closed circles represent the carboxylate and ammonium groups as the triple hydrogen bond donors and acceptors, respectively. In the crystal structures (right), the small circles show hydrogen atoms attached to nitrogen atoms, and dotted lines show hydrogen bonds. The other hydrogen atoms and substituents are omitted for clarity. Types I-IV are seen in the non-polymerizable crystals of ammonium sorbates, and types V-VII in the non-polymerizable crystals of ammonium muconates.

most important factor for the polymerizable monomer crystals. However, these distance values for these stacking styles of types I-VII are greater than the ideal one $(\sim 5 \AA)$ for polymerization, or the hydrogen bond network runs parallel to the molecular plane of the muconates, which are aligned in a sheet. We have pointed out that the isomerism of 1D ladder hydrogen bond structures is important for the topotactic EZ-isomerism in the crystalline state under UV irradiation. ${ }^{86}$

We further investigated the monomer crystal structures to clarify the role of weak intermolecular interactions for the molecular packing and the isomerism of the hydrogen bond networks. ${ }^{85}$ Figure 9 shows the crystal structures of the polymerizable salts, which are shown as the side view of the stacking structure of the anion and cation layers in an alternating fashion. For the construction of the lamellar structure, $\pi-\pi$ stacking and $\mathrm{CH} / \pi$ interaction are important for packing in the lipophilic layer. Figure 9 also represents $\mathrm{CH} / \pi$ interaction between the primary ammonium cations in the ammonium cation layer. A similar crystal structure and interaction are observed for the crystals of both the sorbates and muconates, irrespective of their mono- and dianion structures.

The aromatic rings in the countercations of all the polymerizable salts involve $\mathrm{CH} / \pi$ interaction to support the columnar arrangement of the diene parts. They are classified into two categories; one is the parallel arrangement that aromatic groups are stacked in a layer by the translational packing along two axes. In these crystals, $\mathrm{CH} / \pi$ interaction is observed in the orthogonally different directions in a plane. The crystals with a highly symmetrical structure have translationaltype packing. Another is a herringbone-type arrangement. In these crystals, the aromatic rings translationally stack only along an axis. The difference in the 
(a)

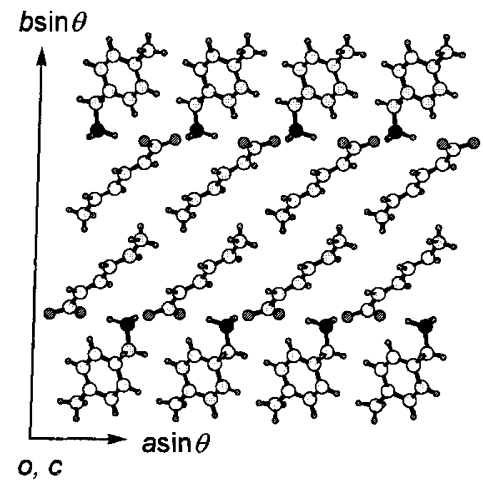

(b)
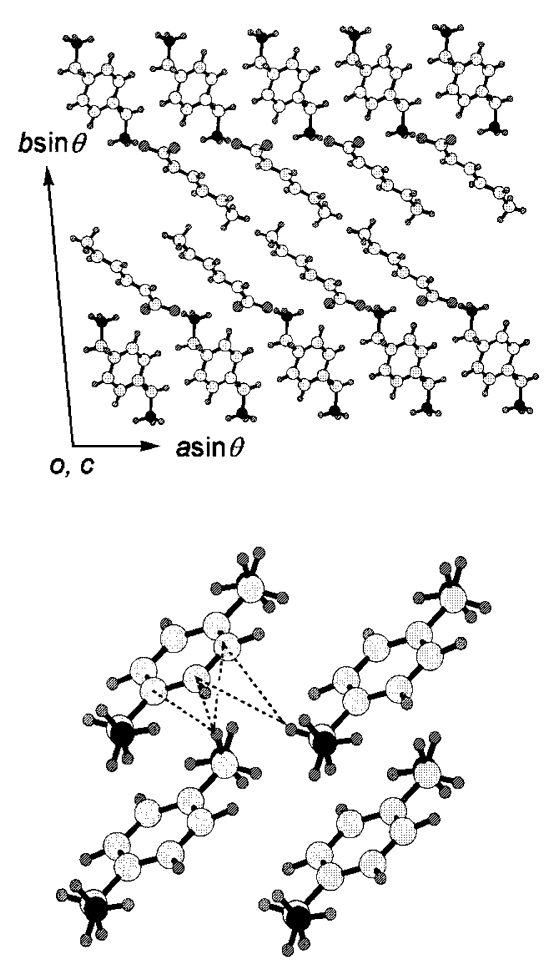

(c)
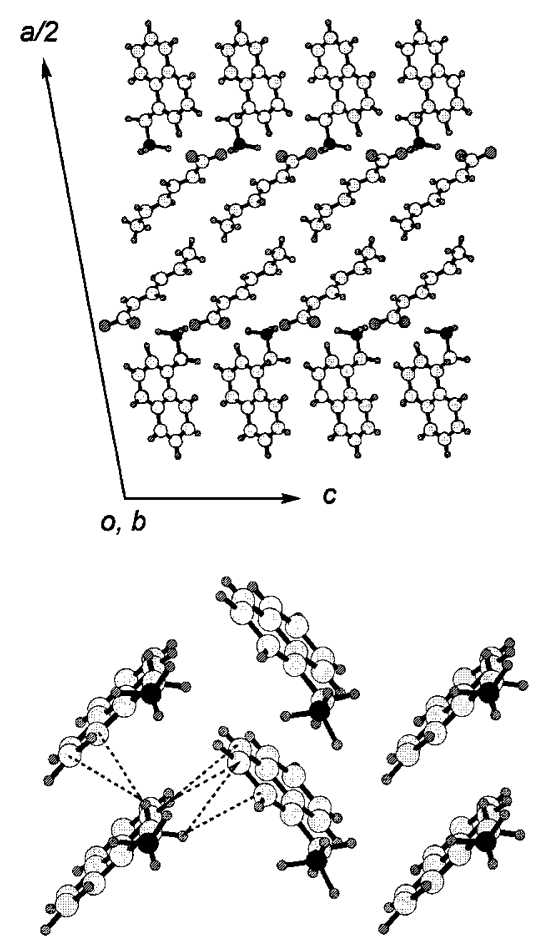

Figure 9. Side view of an anion layer sandwiched between cation layers viewed down along the crystallographic an axis (top). $\mathrm{CH} / \pi$ interactions between the aromatic groups in the ammonium cation layers (bottom). Dotted lines represent the close contacts of the carbon and hydrogen atoms. (a) 5a, (b) 6a, and (c) 5c.

styles of the $\mathrm{CH} / \pi$ interaction is related to the difference in the 2D hydrogen bond network; when the ammonium cation parts have a herringbone style, the 2D hydrogen bond network favors an anti-parallel structure.

The halogen-halogen interaction as supramolecular synthons has a significant potential in the presence of other weak interactions (for example, $\mathrm{CH} / \pi$ interactions) and is used for rational crystal design of the diene monomers other than the ammonium derivatives. The control of the molecular alignment through a halogenhalogen interaction is effective when any robust interaction such as a hydrogen bond is absent, as seen in the case of the ester derivatives. ${ }^{42}$

From the viewpoint of intermolecular force for the monomer stacking, the following facts support the existence of a halogen-halogen interaction in the crystals of several muconic ester compounds. Initially, the distances between the non-bonding halogen atoms (for example, $3.57 \AA$ and $3.63 \AA$ in the crystals of $1 \mathbf{c}$ and 1d, respectively) are shorter than the sum of the corresponding van der Waals radii. Secondly, the Kitaigorodskii rule ${ }^{53}$ breaks down in this case, despite the validity of the rule for a large number of the other crystals of nonpolar and various shaped aliphatic molecules. The replacement of one by the other would not change their crystal structure when packing is governed by the Kitaigorodskii rule. The substituent groups have no significant difference in their volumes $\left(20 \AA^{3}\right.$ for $\mathrm{Cl}$, $26 \AA^{3}$ for $\mathrm{Br}$, and $24 \AA^{3}$ for $\mathrm{CH}_{3}$ ). Nevertheless, the crystal structure of the 4-methyl-substituted monomer is completely different from those of the 4-chloro- and 4-bromo-substituted derivatives. ${ }^{42}$ A similar structural motif with the halogen chain is also observed for the crystals of halogens such as $\mathrm{Cl}_{2}, \mathrm{Br}_{2}$, and $\mathrm{I}_{2}$. The alignment of the dibenzyl muconate monomers in the crystals is regulated by the characteristic halogen zigzag chains as a supramolecular synthon, which may be applicable for the crystal design of halogen-containing ester derivatives.

The selection of halogen atoms as well as the position of substitution may be important for crystal designs based on halogen-halogen interaction. The fluorosubstituted analogue does not form such a halogen chain because of a weak interaction between the fluorine atoms. The undesired crystal packing and no polymerization results due to the meta-substitution suggest the important role of the position of the halogen atom in determining the pattern of the halogen interaction in the crystals. These monomers produced an aromatic stack of the benzyl groups characterized by a short stacking distance. The resulting $d_{\mathrm{s}}$ values are too short to be suitable for photopolymerization.

The halogen-substituted ethyl esters (for example, 2chloro- and 2-bromoethyl esters) form no zigzag chain 
(a)

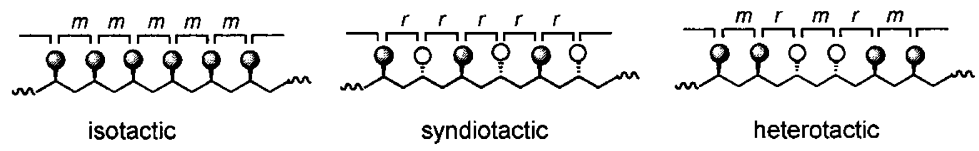

(b)
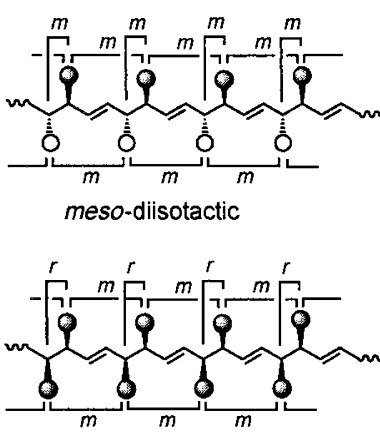

racemo-diisotactic
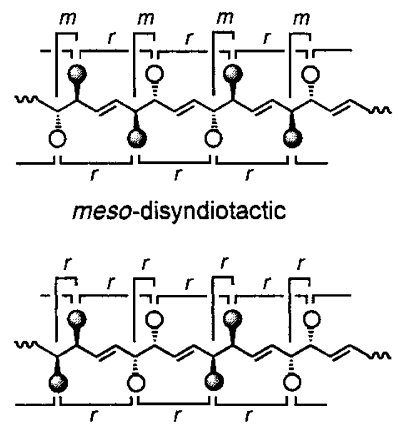

racemo-disyndiotactic

(c)
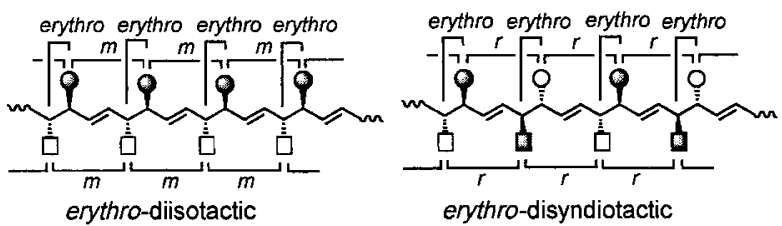

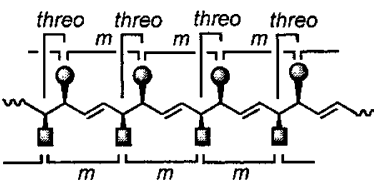

threo-diisotactic

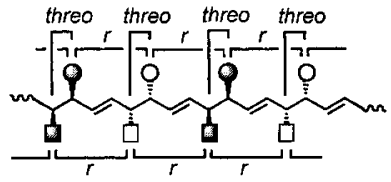

threo-disyndiotactic

Figure 10. (a) Three kinds of stereoregular polymers obtained from vinyl monomers. (b) Four kinds of stereoregular trans-1,4 polymers obtained from a symmetric 1,4-disubstituted 1,3-butadiene. (c) Four kinds of stereoregular trans-1,4 polymers obtained from an asymmetric 1,4-disubstituted 1,3-butadiene. $m$ and $r$ indicate meso and racemo diads, respectively.

structure although the halogen atoms closely contact each other in these crystals. This supports the role of the aromatic rings in the columnar alignment. In the crystals of $\mathbf{1 c}$ and $\mathbf{1 d}$, the molecules are connected by a $\mathrm{CH} / \pi$ interaction as well as halogen chains to strengthen the columnar structure appropriate for the polymerization. The control of the molecular alignment through a halogen-halogen interaction is effective in combination with any other weak interaction.

More recently, we have already found that the combination of the $\mathrm{CH} / \pi$ interaction with the $\mathrm{CH} / \mathrm{O}$ interaction is useful for the design of the topochemical polymerization to yield a new type of stereoregular poly$\operatorname{mer}^{43}$ (see the next section). We have also noticed that another type of supramolecular synthon to form a $5 \AA$ stacking distance. It is well-known that the primary and secondary amides form robust hydrogen-bonded ribbons, tapes, and sheets as the structural motifs for crystal engineering. ${ }^{76,77}$ This is possible that the secondary amides of muconic and sorbic acids form linear hydrogen bonds via the bidentate interaction between the $\mathrm{N}-\mathrm{H}$ and $\mathrm{C}=\mathrm{O}$ groups at the ideal stacking distance of $5 \AA$. However, no polymerization proceeded in the direction of the 1D hydrogen bond chain despite the appropriate stacking distance. It is due to the unfavorable direction of the diene moieties for the $\pi-\pi$ stacking of the sorbates and muconates. As is briefly described in the previous section, we recently revealed a sheet-type arrangement in the crystals of the sorbamide derivatives $(\mathbf{7 a}-\mathbf{7 e})$ in which linear hydrogen bonds supported the sheet structure and the polymerization occurred between the inter-sheets by the introduction of a naph- thylmethyl and long alkyl groups as the $N$-substituents, resulting in the situation of the diene moieties by the stacking of the sheets in an appropriate sheet-to-sheet distance and phase. ${ }^{51}$

\section{POLYMER STRUCTURE CONTROL}

\section{Tacticity}

The stereochemistry of vinyl and diene polymers is well controlled during coordination and ionic polymerizations, where any metal ion is involved as the species due to eminent coordination properties at the chain end leading to the control of the polymer stereoregularity. Figure 10a shows the illustrative representation of isotactic, syndiotactic, and heterotactic polymers as the most typical stereoregular polymers obtained from ordinary head-to-tail propagation of vinyl monomers. In the isotactic polymer chains, asymmetric carbon centers in the main chain have the same sign as the absolute configuration. In the case of syndiotactic polymers, the carbons with both configurations appear alternatingly along the polymer chains. The stereochemical relationship between two successive repeating units is represented by the terms meso $(m)$ and racemo $(r)$ for isotactic and syndiotactic diads, respectively. A heterotactic polymer has a highly regulated repeating structure, in which meso and racemo diads appear alternatingly along the chain.

The polymerization of diene monomers results in polymers of more complicated stereochemistry rather than vinyl polymers. The polymerization of butadiene or isoprene may result in three kinds of configu- 


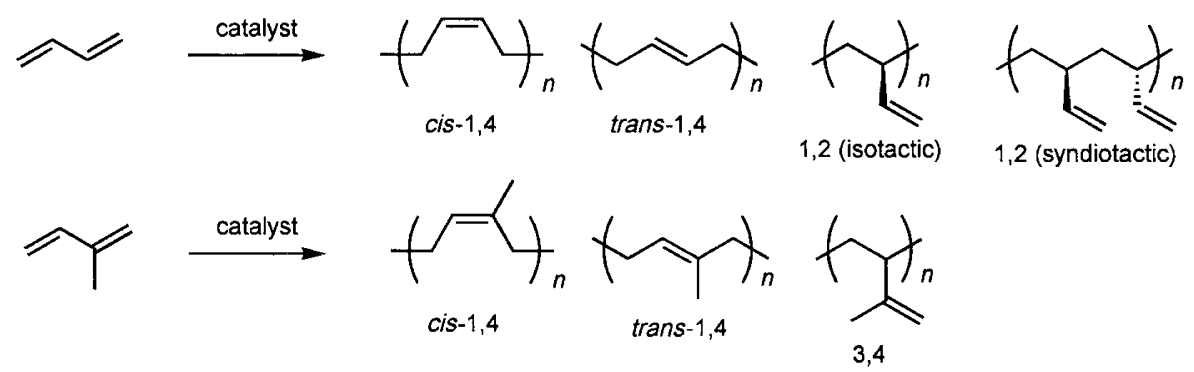

Scheme 4

Table IV. Stereospecific polymerization of 1,3-butadiene

\begin{tabular}{|c|c|c|c|c|}
\hline \multirow{2}{*}{ Catalyst } & \multicolumn{3}{|c|}{ Microtacticity } & \multirow{2}{*}{ ref } \\
\hline & cis-1,4 & trans $-1,4$ & 1,2 & \\
\hline $\mathrm{TiI}_{4}-\mathrm{Al}(i-\mathrm{Bu})_{3}$ & 94 & 2 & 4 & 92 \\
\hline $\mathrm{CoCl}_{2}(\text { py })_{2}-\mathrm{AlEt}_{2} \mathrm{Cl}$ & 96 & 2.1 & 1.9 & 93 \\
\hline $\mathrm{Ni}(\mathrm{OCOR})_{2}-\mathrm{AlEt}_{3}-\mathrm{BF}_{3} \mathrm{OEt}_{2}$ & 98.4 & 0.6 & 1.0 & 91 \\
\hline $\mathrm{NdCl}_{3}-\mathrm{C}_{2} \mathrm{H}_{5} \mathrm{OH}-\mathrm{Al}(i-\mathrm{Bu})_{3}$ & 98.6 & 1.1 & 0.3 & 91 \\
\hline $\mathrm{U}(\pi \text {-allyl })_{3} \mathrm{Cl}$-AlEtCl${ }_{2}$ & 99 & 0.7 & 0.3 & 94 \\
\hline Samarocene-modified $\mathrm{MAO}^{\mathrm{a}}$ & $>99.5$ & $<0.1$ & 0.4 & 95 \\
\hline $\mathrm{VCl}_{3}-\mathrm{AlEt}_{3}$ & 0 & 99 & 1 & 12,96 \\
\hline $\mathrm{Mt}$ (versatate)- $\mathrm{AlEt}_{3}-\mathrm{MgBu}_{2}{ }^{\mathrm{b}}$ & 1.0 & 98.7 & 0.3 & 97 \\
\hline $\mathrm{V}(\mathrm{acac})_{3}-\mathrm{AlEt}_{3}$ & $3-6$ & $2-4$ & 90-95 (syndiotactic) & 12,98 \\
\hline $\mathrm{Co}(\mathrm{acac})_{3}-\mathrm{AlEt}_{3}-\mathrm{H}_{2} \mathrm{O}-\mathrm{CS}_{2}$ & $\sim 1$ & 0 & $>99$ (syndiotactic) & 99 \\
\hline $\mathrm{C}_{4} \mathrm{H}_{9} \mathrm{Li}$ (bispiperidinoethane) & 0 & 0 & $\sim 100$ (atactic) & 100 \\
\hline
\end{tabular}

${ }^{\mathrm{a}} \mathrm{Cp}{ }_{2} \mathrm{Sm}\left[(m-\mathrm{Me}) \mathrm{AlMe}_{2}(m-\mathrm{Me})\right]_{2} \mathrm{SmCp}_{2}-\mathrm{Al}(i-\mathrm{Bu})_{3}-\left[\mathrm{Ph}_{3} \mathrm{C}\right]\left[\mathrm{B}\left(\mathrm{C}_{6} \mathrm{~F}_{5}\right)_{4}\right]$. ${ }^{\mathrm{b}}$ Mixture of praseodymium and neodymium.

rations; 1,2 (or 3,4), cis-1,4, and trans-1,4 polymers (Scheme 4). Isotactic and syndiotactic polybutadienes are obtained as the 1,2 structure polymers as well as cisand trans-1,4 polymers according to the selected polymerization conditions, but not all of the possible structures have been synthesized in isoprene polymerization. ${ }^{13}$ Highly controlled stereoregular polymers have been obtained by coordination and anionic polymerizations with modified and newly developed metal-containing catalysts and initiator systems. ${ }^{87-90}$ Table IV summarizes the typical examples of stereospecific polymerization of 1,3-butadiene to give highly controlled stereoregular polymers..$^{91-100}$

The stereochemical structure of polymers produced from 1,4-disubstituted butadienes is represented not only by cis-trans isomerism but also by isotactic-syndiotactic and erythro-threo (or mesoracemo) relationships. ${ }^{48}$ Stereoregular polymers from 1,4-disubstituted butadienes are referred to as tritactic polymers due to the presence of three elements of stereoisomerism for each monomer unit, two pseudoasymmetric carbon centers and a double bond. There are four possible stereoregular structures for trans-1,4 polymers of 1,4-disubstituted butadienes, and these are classified according to whether they originate from symmetrical and asymmetrical monomers (Figures 10b and 10c). The stereochemistry of these polymers is rep- resented by two kinds of relationships, one of which is the relative configuration between the two repeating monomer units. When the configuration of all the carbons with the same substituents is identical, the polymer is diisotactic; in other words, all the repeating relationships are meso in a diisotactic polymer. When the relationships are racemo, the polymer is disyndiotactic. The other relationship is the relative configuration between the vicinal carbon centers, also represented by the terms meso and racemo for a symmetrical structure, and by erythro and threo for an asymmetric structure. Among the possibilities of the formation of many kinds of stereoregular polymers from 1,4-disubstituted 1,3-butadiene monomers in Scheme 5, only two kinds of stereoregular polymers, that is, meso (or erythro)diisotactic and racemo (or threo)-disyndiotactic polymers can be prepared by anionic polymerization with butyllithium in the absence or presence of alkylaluminum compounds, ${ }^{101-103}$ or topochemical polymerization in the solid state. ${ }^{39,48}$

The polymerization of organized monomers is useful for the control of polymer tacticity, although it is generally difficult to control the stereochemical structure of vinyl and diene polymers during radical polymerization in solution. Control of the stereochemical structure of diene polymers is realized in the case of inclusion and topochemical polymerizations in the 


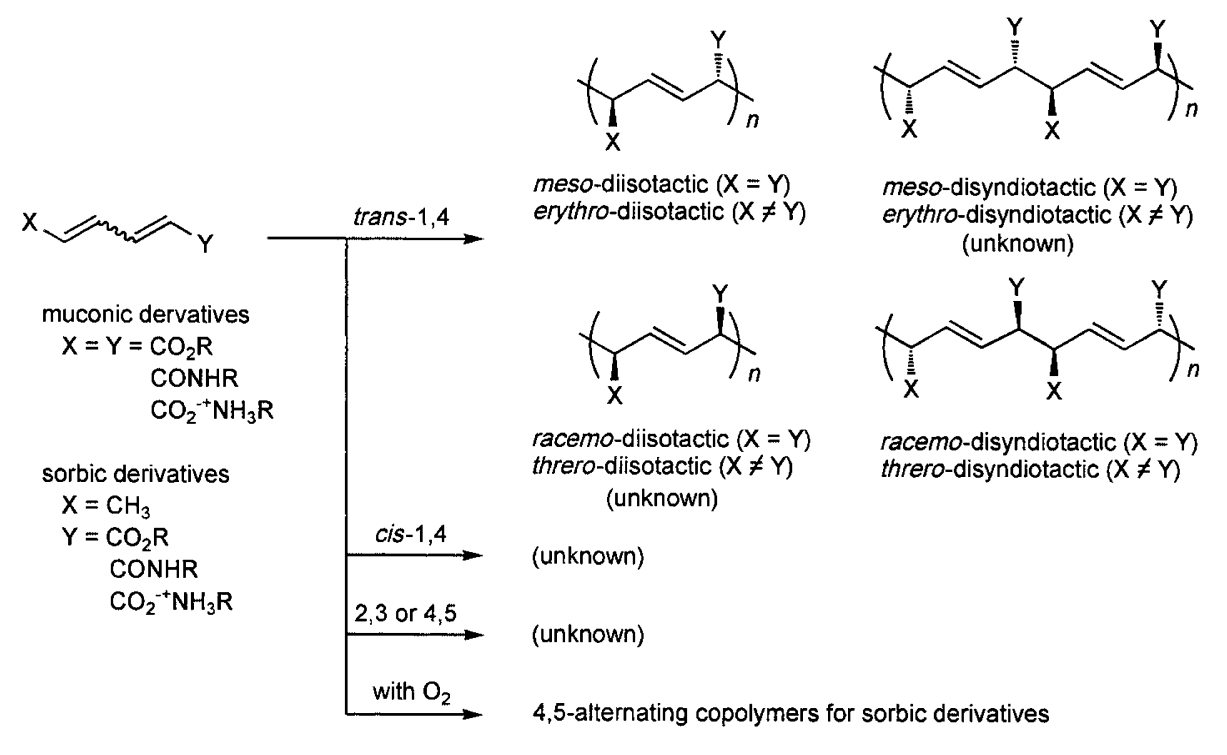

Scheme 5.

solid state. Inclusion polymerization is distinguished from solid-state polymerization of monomers which are themselves crystalline, because the included monomer molecules are not always in the crystalline state due to the considerably high mobility. Monomer molecules are arranged along the direction of a channel in the host crystals, and polymer chains form along the same direction. Not long after the first example of inclusion polymerization in 1956, inclusion polymerization was employed to control polymer structures. ${ }^{27}$ Butadiene and 2,3-dimethylbutadiene, which were included in urea and thiourea, respectively, provided a pure 1,4trans polymer under irradiation with $\beta$-, $\gamma$-, and Xrays. Farina and coworkers opened new areas of inclusion polymerization using perhydrotriphenylene, a tetracyclic saturated hydrocarbon as a new host, which can form inclusion compounds with a wide variety of organic guests. In 1967, 1,4-trans diene polymers, highly isotactic crystalline polymers, were synthesized using this host compound. ${ }^{28,104}$ The first asymmetric synthesis in the solid state was also accomplished by the polymerization of 1,3-trans pentadiene included in the optically active host. ${ }^{105}$ Naturally originated deoxycholic and apocholic acids as well as cycophospazene compounds have also been widely used as host compounds.

Miyata and coworkers ${ }^{30}$ have established, since the late 1980s, the general aspects of inclusion polymerization of vinyl and diene monomers and revealed the intrinsic space effects of these polymerizations. They employed several kinds of steroids to claim that inclusion polymerization should be viewed as a general spacedependent polymerization, not only stereospecific polymerization. The size of the space formed in the channel of the host compounds plays a decisive role in deter- mining the polymerization reactivity of the monomer, as well as the motion of the propagating radicals and the microstructure of the resulting polymer. In larger spaces, the molecular motion is relatively unrestricted, leading to high polymerization rates and a lower degree of stereocontrol. The polymerization of butadiene included in deoxycholic and apocholic acids resulted in a polymer with a less-controlled structure of 1,2-unit up to $30 \%$, and the fraction of 1,2-units depended on the polymerization conditions including the kind of solvent used for the crystallization of the inclusion compounds. In contrast, several methyl-substituted diene monomers such as 1,3-pentadiene, 4-methyl-1,3-pentadiene, and 2,3-dimethyl-1,3-butadiene gave highly controlled 1,4trans polymers by inclusion polymerization with deoxycholic and apocholic acids.

As has already been shown in the previous sections, and also as easily expected, during the topochemical polymerization of 1,3-diene mono- and dicarboxylates such as muconic and sorbic acid derivatives, 2,5trans-meso-diisotactic (or 2,5-trans-erythro-diisotactic for asymmetric monomers) polymers are always produced due to the translational molecular packing in a column in the molecular crystals. ${ }^{48}$ Recently, we have confirmed that a different type of molecular packing is formed in the crystals of the 4-methoxy substituted benzyl ester monomers and that the molecular packing leads to the formation of another type of stereoregular polymer (Figure 11).

In 2002, Tanaka et al. reported the first synthesis of a trans-disyndiotactic polymer as a tritactic polymer through topochemical polymerization using the 4-methoxybenzyl esters of muconic acids ${ }^{42}$ (1e and 3a in Table I). These monomers provide a 2,5-transracemo-disyndiotactic polymer under photoirradiation 
(a)

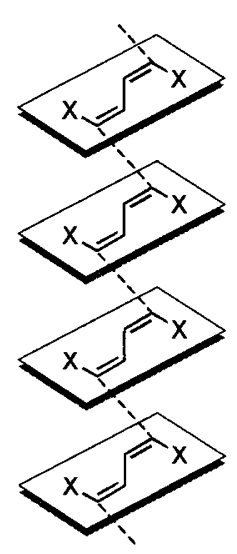

ZZ-isomer

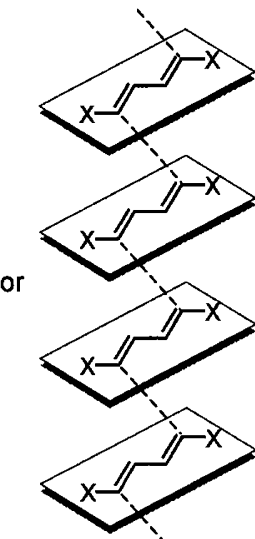

EE-isomer

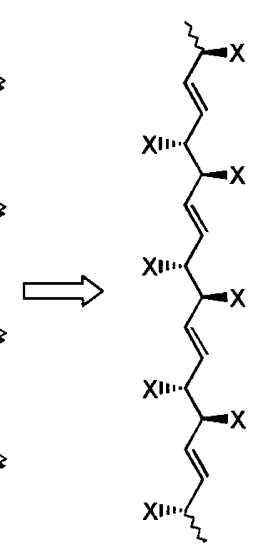

meso-diisotactic- (b)

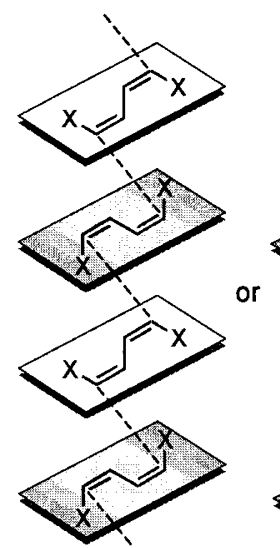

ZZ-isomer

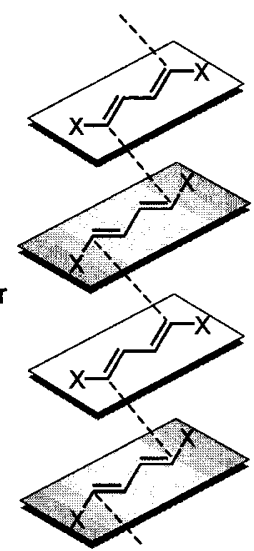

EE-isomer

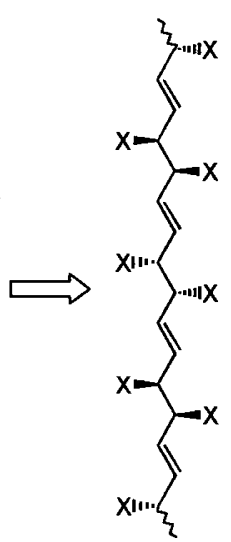

racemo-disyndiotactic1,4-trans structure

Figure 11. Schematic models for (a) diisotactic polymer formation by translational monomer stacking and (b) disyndiotactic polymer formation by alternate monomer stacking.

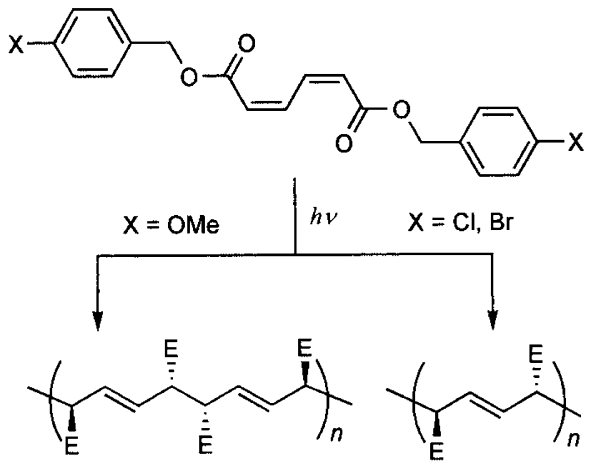

racemo-trans-1,4-disyndiotactic meso-trans-1,4-diisotactic $\mathrm{E}=\mathrm{CO}_{2} \mathrm{CH}_{2} \mathrm{C}_{6} \mathrm{H}_{4} \mathrm{X}$

Scheme 6.

in the crystalline state, as a result of the alternating molecular stacking in a column formed in the crystals with the aid of weak hydrogen bonds such as $\mathrm{CH} / \pi$ and $\mathrm{CH} / \mathrm{O}$ intermolecular interactions, while di(4-halobenzyl) $(Z, Z)$-muconates (1c and 1d) provide diisotactic polymers due to the translational molecular stacking supported by the $\mathrm{CH} / \pi$ and halogen-halogen interactions (Scheme 6).

The photoirradiation of 1e and $\mathbf{3 a}$ in the crystalline state provided an identically structured polymer, while the EZ-derivative had no reaction under similar conditions. The polymer was produced quantitatively under $\gamma$-radiation. The single crystal structures revealed that the monomer molecules are packed in a column in the alternate fashion. The stacking distance of monomer molecules, $d_{\mathrm{s}}$, which was evaluated as the distance between the mass centers of adjacent monomer molecules, is 4.74 and $4.87 \AA$, and the carbon-to-carbon distance between $\mathrm{C} 2$ and $\mathrm{C}^{\prime}$ carbons is 3.44 and $3.32 \AA$ for $\mathbf{1 e}$ and $\mathbf{3 a}$, respectively (Figure 12). These values are very similar to the values reported for other diene monomers providing isotactic polymers. The conformational structure is similar in each case before and after polymerization, being supported by the weak intermolecular interaction between adjacent monomer molecules in a column and inter-columns. The adjacent columns are linked to each other by the $\mathrm{CH} / \mathrm{O}$ interaction between the methoxy groups to form a sheet structure and between the carbonyl oxygen and the hydrogen of a butadiene moiety. The molecular sheets stack alternately to fabricate the molecular stacking structure appropriate for syndiotactic polymerization in the crystals. In the column, close $\mathrm{CH} / \pi$ contact (e.g., 2.84$3.06 \AA$ ) is observed between the benzene ring and the methoxy group. The $\mathrm{CH} / \mathrm{O}$ and $\mathrm{CH} / \pi$ interactions are maintained during the polymerization.

Thus, we have demonstrated that the combination of weak interactions is useful for the design of topochemical polymerization to yield a new type of stereoregular polymer. The weak intermolecular interactions are tolerant of a variety of crystal structure formations to induce a different molecular stacking leading to the different tacticity of polymers, differing from the strong hydrogen bond network, which is robust and credible but inflexible, for the ammonium derivatives. Historically, syndiotactic and disyndiotactic polymerizations of olefins and polar vinyl monomers have followed isotactic and diisotactic polymerizations, as seen in the polymerizations of styrene, propylene, methacrylates, and crotonates, because well-designed and more sophisticated catalysts are required for the control of syndiotactic propagation. ${ }^{106-111}$

The synthesis of cis-1,4 polymers was tried by the use of monomers with an s-cis conformation. Odani et al. attempted the solid-state photopolymerization of 
(a)

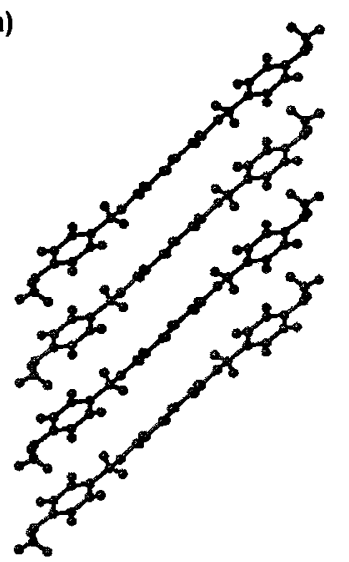

(b)

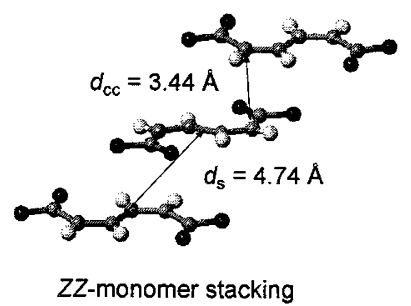

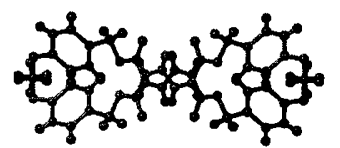

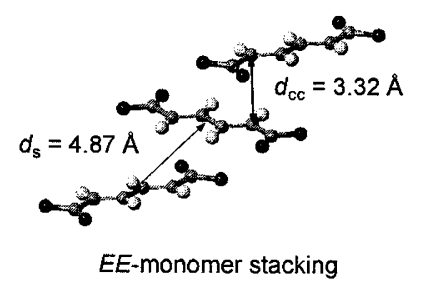

(c)
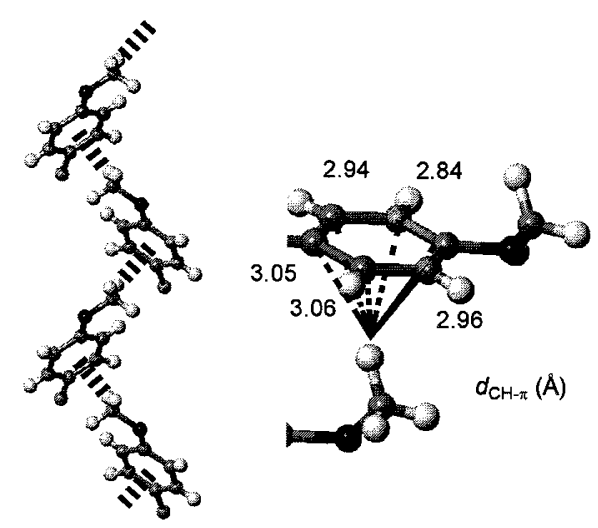

Figure 12. (a) Crystal structures of 1e viewed down along $b$ and $c$-axes. (b) Monomer stacking structure in a column in the crystals of 1e and 3a. (c) Intermolecular $\mathrm{CH} / \pi$ interactions in a column in the crystal of $\mathbf{1 e}$.

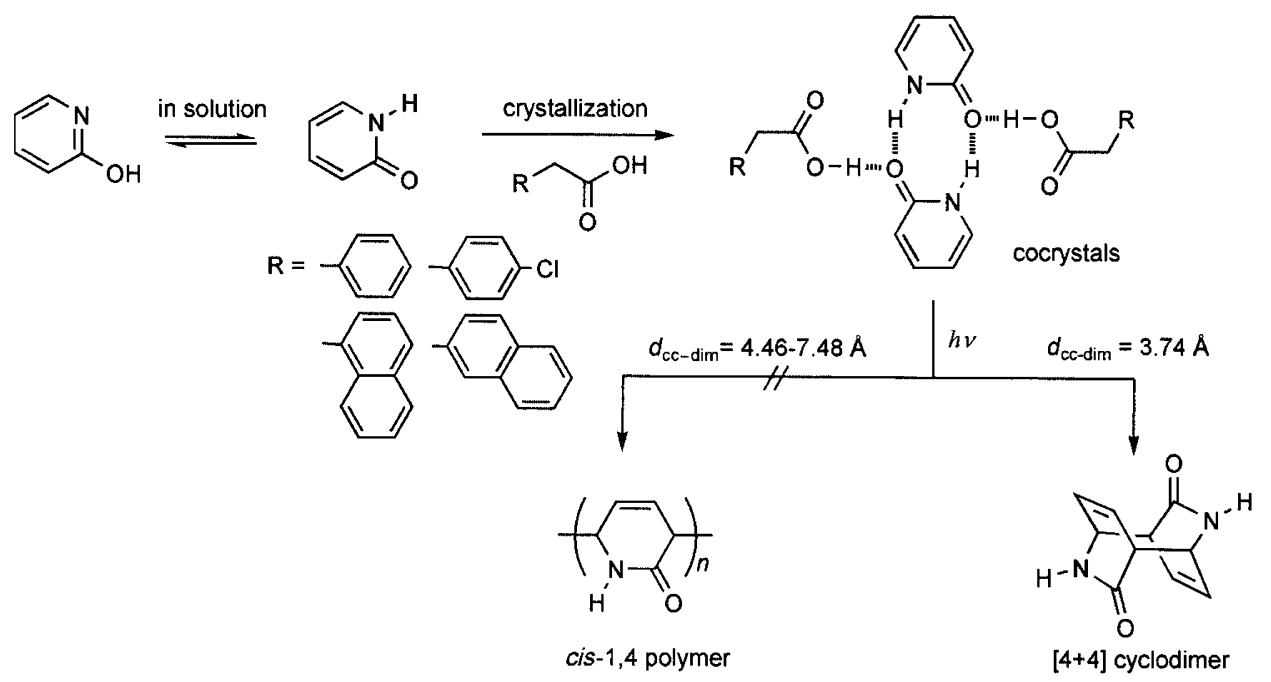

Scheme 7.

pyridone derivatives, which is a six-membered cyclic diene amide and is a tautomer of 2-hydroxypyridine. ${ }^{112}$ Pyridones make hydrogen-bonded cocrystals with a carboxylic acid in the crystalline state, ${ }^{113-115}$ as shown in Scheme 7. Because the cyclic structure fixes its scis conformation, if the polymerization proceeds, a cis2,5 polymer would be obtained. Actually, however, the photopolymerization did not occur, contrary to our expectation, but [4+4] photodimerization proceeded when the carbon-to-carbon distance for the dimerization was small $\left(d_{\mathrm{cc}-\mathrm{dim}}\right.$ less than $\left.4 \AA\right) .{ }^{112}$ A closer stacking distance of the 2-pyridone moieties might be required for the topochemical polymerization of cyclic diene monomers.

2,3 or 4,5 polymers are never known to be produced by the polymerization of the disubstituted 1,3- diene monomers as shown in Scheme 5, but we found a stereospecific 4,5 copolymerization of sorbic esters with oxygen under convenient reaction conditions. ${ }^{116-118}$ The resulting alternating copolymers of the sorbates and oxygen can be used as a new type of degradable polymers for many purposes.

\section{Molecular Weight}

As expected from the characteristics of topochemical polymerization, the size and shape of the polymer crystals depend on the monomer crystals. ${ }^{119}$ The needle crystals of EMU provide similar needle poly(EMU) crystals after polymerization. Radical chain propagation proceeds very fast due to the suitable arrangement of the monomers in the crystals, resulting in the formation of polymers with a molecular weight dependent on 
the crystal size. When the size of the monomer crystals is regulated, the control of the molecular weight and polydispersity is also realized as well as the stereoregularity. Actually, molecular weight control was attempted using the microcrystals prepared by recrystallization, milling, freeze-drying, and reprecipitation as the methods for monomer crystal fabrication. ${ }^{121,122}$ Precipitation was the best method for the preparation of microcrystals, the sizes of which were approximately $10-100 \mu \mathrm{m}$ in length, characterized by a scanning electron micrograph. Gel permeation chromatography revealed that the polymer by precipitation has an $M_{\mathrm{w}}$ of $10^{5}$ and a relatively narrow polydispersity, $M_{\mathrm{w}} / M_{\mathrm{n}}=$ 2.0. The other methods resulted in higher molecular weight polymers with a relatively wide distribution, due to the polydispersity in crystal size. Topochemical polymerization is one of the important techniques for controlling the molecular weight and molecular weight distribution of the polymers based on a concept completely different from the other reported methods, for example, living polymerization, template polymerization, synthetic organic approach, genetic engineering, and chromatographic separation.

The monomer crystal size influences not only the molecular weight but also the yield of the polymer produced, as observed for photo- and $\gamma$-ray induced polymerizations. ${ }^{64}$ For the $\gamma$-ray radiation polymerization, the initiation should occur throughout the crystals because of the excellent $\gamma$-ray penetration, but it was reported that large-size crystals prepared by conventional recrystallization afforded higher polymer yields than those for microcrystals prepared by freeze-drying under similar radiation conditions. The monomer crystals sieved by crystal size provided a different polymerization yield after an identical radiation dose. Due to the polymerization reactivity depending on the crystal size, it is difficult to evaluate the kinetics of the polymerization. However, the polymerization rate can be determined by the IR spectroscopy of thin crystal samples using the $\mathrm{KBr}$ method. The thin monomer crystals dispersed in $\mathrm{KBr}$ are irradiated with a high efficiency independent of the type of monomers and its crystal habit. The polymerization kinetics is apparently considered a first-order reaction, and the determined kinetic constants are indices of the reactivity of the monomers for the polymerization in the crystalline state. ${ }^{120}$

Recent developments in apparatus and techniques of scanning probe microscopies and mass spectrometry would open a new approach to the evaluation of the molecular weight of polymers. Especially, these analytic methods are indispensable for direct determination of the molecular weight of polymers formed by the topochemical polymerization micro- and nano-crystals.
In the future, the characterization of polymers will be carried out using a piece of thin crystal, that is, a "single" crystal.

\section{Ladder Structure}

Topochemical polymerization would possess further potential to provide polymers with a more sophisticated structure. ${ }^{123}$ For example, a bifunctional monomer, in which the two reacting groups are linked to a stacking group, may provide a ladder polymer by appropriate arrangement of the monomer molecules in the crystals. The synthesis of three-dimensionally controlled polymers from multi-functional monomers has been considered to be difficult through a chain reaction such as radical polymerization accompanying crosslinking as a side reaction. In contrast, the topochemical polymerization of bifunctional monomers is expected to provide a ladder polymer without any cross-linking reaction. In general, there are several strategies for the synthesis of ladder polymers. ${ }^{124}$ Condensation polymerization includes a growing step of the double-stranded chain. Another approach is the synthesis of single-stranded polymers carrying required functionalities along the polymer chain, followed by the formation of the second strand. Both strategies have serious problems for controlled synthesis due to the incomplete chain growing reaction and undesired side reactions. Alternatively, Diels-Alder polyaddition is used for ladder polymers with well-defined structures using bifunctional components with both diene and dienophile functionalities. ${ }^{125,126}$ Another problem of the ladder polymer synthesis is the difficult polymer characterization due to poor solubility, as has been shown during the solid-state polymerization of diacetylene derivatives. ${ }^{127-129}$ We adopted alkylenediammonium disorbate monomers as the candidate for a bifunctional diene monomer for ladder polymer synthesis through topochemical polymerization. ${ }^{130}$ The dicationic part in the polymers can be converted to other counter parts such as monocations via a solid-state polymer transformation to determine the structure of the corresponding single-stranded chains in solution.

When the crystals of $\mathbf{6 a}$ were photoirradiated with a high-pressure mercury lamp under atmospheric conditions, an insoluble polymer was produced. The polymer yield increased with an increase in the reaction temperature and reached $96 \%$ yield at $100{ }^{\circ} \mathrm{C}$. $\operatorname{Poly}(\mathbf{6 a})$ was insoluble in all solvents, including a common organic solvent and fluorine-containing polar solvents such as trifluoroacetic acid. From the powder X-ray diffraction profiles, the interplanar distances were calculated to be 16.9 and $17.2 \AA$ for $\mathbf{6 a}$ and poly(6a), respectively, indicating the thickness of the lamella structure consisting 
of the sorbate anion and xylylenediammonium layers. We have also successfully determined the single crystal structure of 6a, which indicates an appropriate crystal for topochemical polymerization.

The side chain of poly(6a) can be converted to any other counter part by a polymer reaction in the solid state. Poly $(\mathbf{5 c})$ as the single strand polymer was quantitatively hydrolyzed under mild conditions, for example, $1 \mathrm{M} \mathrm{HCl}$ in aqueous methanol at room temperature, but double strand poly(6a) was only partly hydrolyzed under identical conditions. With $6 \mathrm{M} \mathrm{HCl}$ under reflux in methanol, the protonation completely proceeded to give poly(sorbic acid), PSA. The acid resistance of poly $(6 \mathbf{6 a})$ is due to the robust structure of the doublestranded polymer crystals. PSA derived from poly(6a) was further converted to poly(triethylammonium sorbate), of which the ${ }^{13} \mathrm{C}$ NMR spectrum indicated the highly controlled erythro-diisotactic-2,5-trans structure of the polymer. The robust structure of the polymer influenced not only the hydrolysis but also the thermal decomposition behavior. The decomposition of singlestrand ammonium polymers proceeded in two steps due to the side chain decomposition accompanied by the liberation of the amine in the first step to give PSA, but no clear two-step decomposition was observed in the thermogravimetric curve of $\operatorname{poly}(\mathbf{6 a})$.

There are two types of models for the solid-state polymerization of bifunctional monomers as the extreme case. In Case I, both functional groups in one monomer molecule may simultaneously react to give a ladder polymer without any pendant group. On the other hand, either side part of the dienes exclusively reacts to give a polymer with unreactive groups as the pendant in Case II. If a drastic conformation change in the monomer moiety in the crystals is accompanied by propagation, the conversion does not exceed $50 \%$ and a polymer with a pendant group is produced. Polymer chains would be randomly formed, as the intermediate of Cases I and II. When the isolated polymer is hydrolyzed, the parts of the linker in the polymer are removed. In Cases I and II, the residual weight of the isolated PSA after the hydrolysis would be 62 and 31\% of the weight of the original polymer, respectively. The experimental values $(58 \%)$ of the residual weight after the hydrolysis was close to that expected for Case $\mathrm{I}$, independent of the irradiation time and the polymer yield. The constant value of reduced viscosity, regardless of the polymer yield, supports the formation of a high molecular weight polymer during the early stage of polymerization via fast propagation in a radical chain mechanism. If the polymer contains any pendant group, a sorbic acid monomer would be contained in the soluble part. However, it was not detected in the NMR spec- (a)
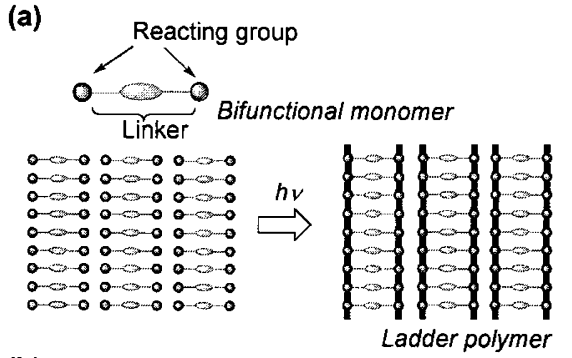

(b)

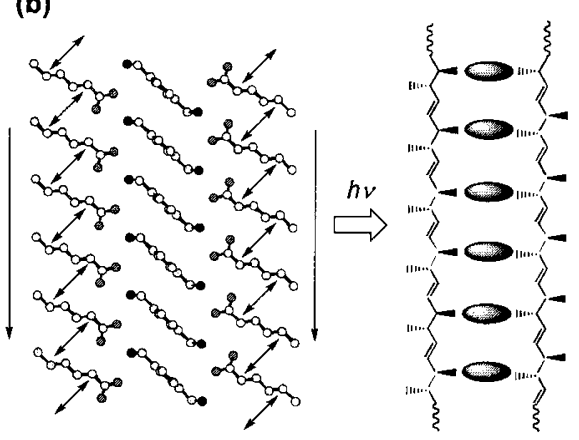

Figure 13. (a) Molecular model of a ladder polymer obtained from a bifunctional monomer by topochemical polymerization. (b) Stacking structure of $\mathbf{6 a}$ in the crystals and stereochemical structure of the polymer. The two reaction parts of the monomer are synchronized to simultaneously react with the conformational change in a sorbate moiety. The change is transformed into another sorbate through the diammonium part as the linker.

trum after hydrolysis. This indicates that the polymer has no pendant group and that polymerization proceeds exactly via a reaction mechanism in Case I.

Consequently, we proposed a model for the reaction mechanism to provide a ladder polymer in the crystalline state (Figure 13), based on the results of single crystal structure analysis and the observation of the $\alpha$ methyl and $\alpha$-carboxylate propagating radicals by ESR spectroscopy. The two reaction parts of the monomer are synchronized to simultaneously react with the conformational change in a sorbate moiety that is transformed into another sorbate through the diammonium part as the linker. Because sorbic acid is a 1,3-butadiene derivative having different substituents at the 1- and 4positions, $\alpha$-methyl and $\alpha$-carboxylate radicals are possibly formed. When an ESR measurement was carried out to detect the propagating radicals during UV irradiation of $\mathbf{6 a}$ in the crystalline state, the observed spectrum consisted of broad lines with a $g$-value of 2.0029 , and its line-width was larger than that of $\mathbf{2} \mathbf{f}$ as the symmetric structure monomer. Considering the ESR coupling constant values reported for the propagating radical of $\mathbf{1 a}$ and 2,4-hexadiene in solution, the propagating radicals of $6 \mathbf{a}$ are speculated to be the $\alpha$-methyl and $\alpha$-carboxyl radicals during polymerization in the crystalline state. During the polymerization of the conjugated diene monomers in solution, the participation of both radicals during the propagation has not been 
reported. This reaction mechanism is peculiar to the solid-state polymerization.

For a long time, it has been considered that a ladder polymer with a well-controlled structure is not prepared via a chain reaction such as radical polymerization. However, we have proposed a new route to the efficient synthesis of a ladder polymer via a radical chain polymerization using topochemical polymerization of a bifunctional monomer in the crystalline state. Any conformational change in a sorbate moiety can be transformed into another sorbate group through the diammonium part in the crystals. Consequently, the two reaction parts are possibly synchronized to react at the same time.

\section{MATERIALS DESIGN BY ORGANIC INTERCALATION}

In intercalation reactions, molecules or ions as the guest species are reversibly inserted into a layered host solid without major rearrangement of the structural features of the host. ${ }^{131,132}$ A host compound recognizes guest species and accepts them with a reversible change using non-covalent bonding. Intercalation reactions are typically seen in inorganic materials such as graphite, clay, and metal oxides. The mechanism of the reactions and the properties of the obtained layered products have been intensively investigated for systems consisting of inorganic layered solids as the host in combination with various kinds of inorganic and organic components as the guest species. ${ }^{133-141}$ In contrast to a variety of intercalation hosts made of inorganic compounds and inorganic-organic hybrids, very few examples of intercalation systems using organic compounds as both the host and guest are known. A limited number of organic crystals have been reported as the organic mimics of clay. ${ }^{142-148}$ Intercalation chemistry is important to develop advanced materials such as heterogeneous catalysts, ionic and protonic conductors, specific adsorbents, nonlinear optics, photonic devices, and nanocomposites.

Layered polymer crystals obtained by the topochemical polymerization of alkylammonium muconates and sorbates function as an intercalation compound ${ }^{149-151}$ (Figure 14). For example, the ammonium muconate polymer crystals are converted into poly(muconic acid) (PMA) crystals by hydrolysis with $\mathrm{HCl}$ in an aqueous methanol or by thermolysis in the solid state, and the process is reversible. Alkylamine molecules are intercalated into the PMA crystals dispersed in a methanol solution of the amine with stirring at room temperature. Namely, the ammonium layers can be removed and inserted in the polymer crystals, as shown in Scheme 8.

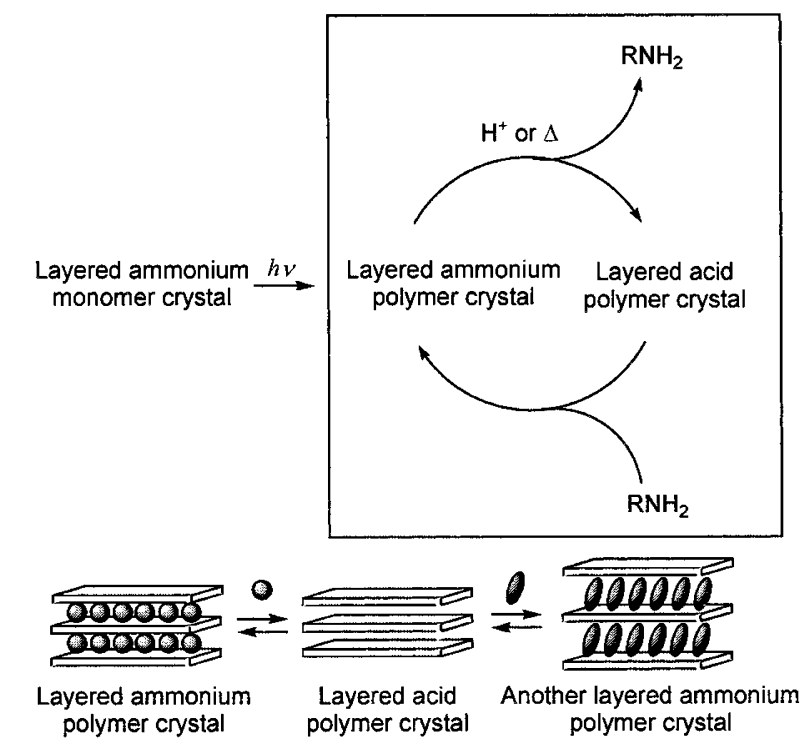

Figure 14. Schematic model of organic intercalation with layered polymer crystals.

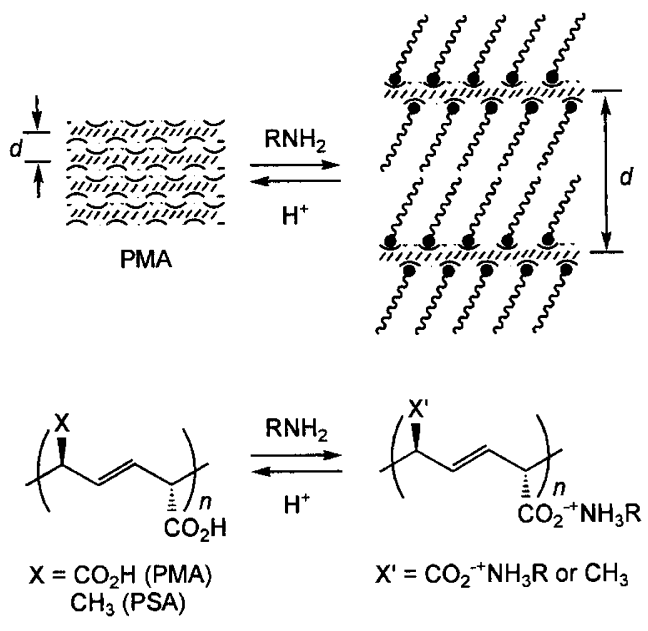

Scheme 8.

These transformations are heterogeneous because both the polymer crystals as the acid and the ammonium salts are insoluble in methanol as the dispersant. Nevertheless, intercalation proceeds with a high efficiency to achieve a high conversion when an $n$-alkylamine is used as the guest molecule. Repeated cycles of the ammonium-acid transformation provide similar polymer crystals without serious damage or collapse of the layer structure despite a drastic change in the chemical and crystallographic structures during the reactions. More recently, we have revealed that similar intercalation occurs when the crystals of PSA are used in place of PMA. ${ }^{151}$

When an intercalation was carried out with various kinds of $n$-alkylamines, the conversion increased with an increase in the carbon atom number $(\mathrm{m})$ and the molar ratio of the used $n$-alkylamines $\left(\left[-\mathrm{NH}_{2}\right] /\left[-\mathrm{CO}_{2} \mathrm{H}\right]\right)$. The intercalation into PMA was performed at a high efficiency of more than $95 \%$ when a large excess of 
(a)

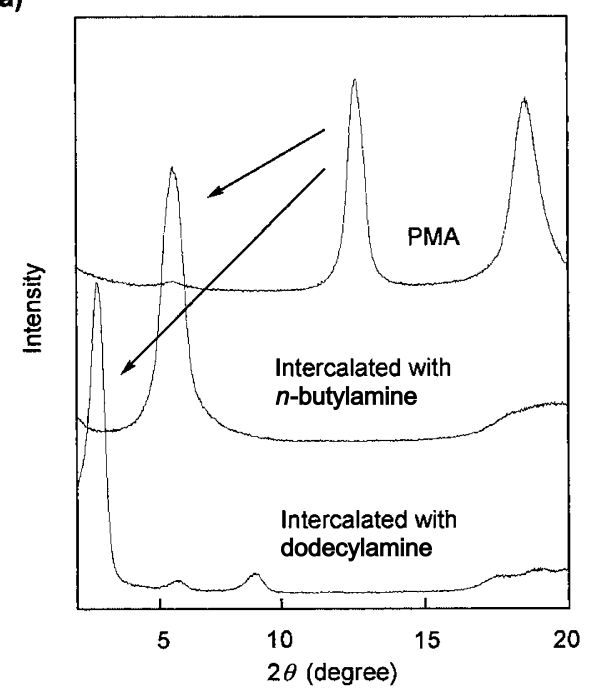

(b)

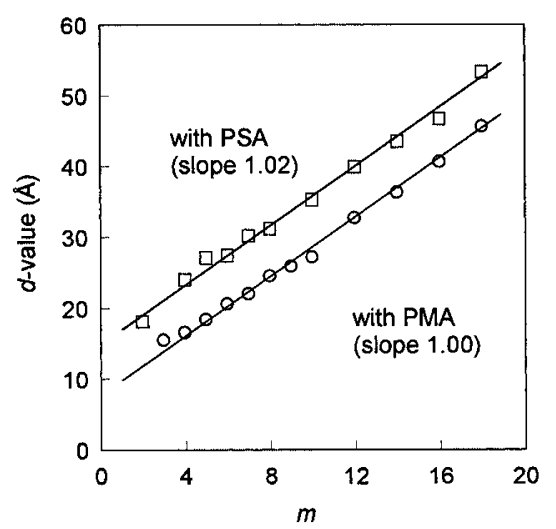

Figure 15. (a) Wide-angle powder X-ray diffraction profiles of PMA crystals before and after intercalation of $n$-alkylamines; PMA before intercalation $(d=4.8 \AA)$, after intercalation with $n$ butylamine $(d=16.5 \AA)$, and after intercalation with dodecylamine ( $d=32.6 \AA$ ). (b) Change in the $d$ value for (O) PMA and ( $\square$ ) PSA as a function of the carbon number of the $n$-alkylamine $(m)$. The slope of both the lines is equal to $1.0 \AA$ per increment in the carbon number.

the amines including a long-alkyl chain was used (10fold equivalent and $m>12$ ). The reaction proceeded rapidly and reached a constant conversion within several hours, irrespective of the structure of the alkylamine used. The time dependence of the conversion revealed the accelerated intercalation of amines with a longer $n$-alkyl group. Similar intercalation was also examined with PSA in place of PMA. Differing from the facile intercalation with PMA, however, PSA as the host compound resulted in a low conversion even when a long-chain alkylamine was used. A large excess of the guest amine was necessary to obtain a quantitative conversion for the intercalation using PSA.

Figure 15a shows a typical change in wide-angle powder X-ray diffraction profiles for PMA intercalated with different $n$-alkylamines. The value of the inter- layer spacing $(d)$ was determined from the $2 \theta$ value for the characteristic peaks observed at a low-angle region in the diffraction profiles, being assigned on the basis of the reported single crystal structures of alkylammonium muconates. The $d$ value depends on the size of the alkyl group of the amine used; from $4.8 \AA$ for PMA to 16.5 and $32.6 \AA$ for the polymers intercalated with $n$ butyl- and dodecylamines, respectively. The latter profile agreed well with that $(d=31.7 \AA)$ for the polymer crystals obtained by direct topochemical polymerization of the corresponding alkylammonium monomer.

The $d$ values for PMA and PSA crystals intercalated with various $n$-alkylamines are summarized in Figure $15 \mathrm{~b}$. The $d$ value increased with an increase in the $m$ value for each series of PMA and PSA intercalation. Both the polymer crystal series produce an exactly identical slope; the thickness of the alkylamine layer increases by 1.00 and $1.02 \AA$ for each carbon in the $\mathrm{N}$-alkyl substituent, for the PMA and PSA series, respectively. Accordingly, the alkyl chains of the amines stacked in the layers have a similar tilt structure, despite the differences in the polymer chain structure and also in the reaction behavior during the intercalation. The tilt angle of the alkyl chains intercalated with $n$ alkylamine is determined to be $38^{\circ}$ relative to $2 \mathrm{D}$ polymer sheet of PMA and PSA crystals. This is calculated from an increment in the $d$-values depending on the carbon number of the alkyl groups in the $n$-alkylamines as the guest in consideration of the distance of repeating units $(2.54 \AA)$ for the trans zigzag chain of alkanes. These results confirm the stacking structure of the alkylammonium counterparts with a tilt but not an interdigitation structure.

The PMA and PSA crystals are prepared by the hydrolysis of the ammonium polymer crystals of muconic and sorbic acids, respectively, because both the acids have no polymerization reactivity. The appearance of the crystals of the precursor ammonium polymers is the same as those of the corresponding ammonium monomer crystals because the polymerization occurs via a crystal-to-crystal process in a topochemical reaction mechanism. The apparent crystal shape such as a crystal habit has no change on a macroscopic scale except for the thickness of the needles and also the volume of crystals during the hydrolysis and intercalation in the solid state. The highly ordered and stacked layers are indispensable for successful intercalation reactions. A specific surface of the crystals acts as the entrance for the guest molecules, possibly from the sides of the stacked layers. A cooperative structural change in the stacked layers is the key to the quantitative insertion of the guests and the drastic change in the crystal layer structure during the reaction. Polymer chains in 
(a)

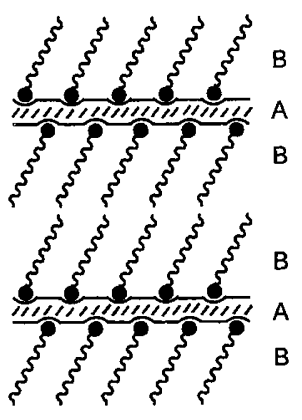

(b)

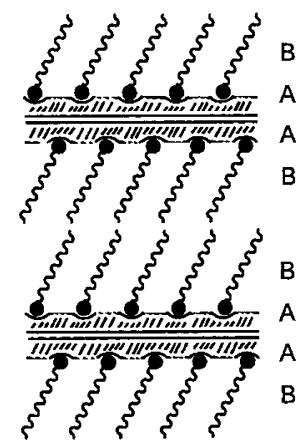

Figure 16. Model of layered ammonium polymer crystals obtained from (a) PMA and (b) PSA.

the polymer crystals with a stereoregular structure are aligned with the specific axis of the crystals and linked to each other by a 2D hydrogen bond network. Covalent bonds along the polymer chain as well as hydrogen bonds connecting polymer chains support the reversible solid-state transformation between the acid and ammonium polymers. The cooperative process of the insertion of the molecules and the formation of restructured layers is indispensable for quantitative transformation.

The polymer crystals of the ammonium muconates and sorbates have a layered structure, which is similar to that of the monomer crystals. Figure 16 shows schematic models for the layered structure of the ammonium polymer crystals derived from PMA and PSA. The muconate polymer sheet is sandwiched between two ammonium layers to make a BAB-type stacking unit, where $A$ and $B$ refer to the acid and base layers, respectively. The BAB layers stack further in the crystals. The interface between the A and B layers is tightly fixed by the electrostatic interaction due to the salt formation and by the 2D hydrogen bond network. In contrast, the B layers interact with each other by the weak interaction consisting of van der Waals force. The sorbate polymer crystals have a BAAB-type layered structure, in which not only the B-B but also the A-A interfaces interact with each other by a weak van der Waals force. The incorporation efficiency for the intercalation of alkylamines into the PSA crystals was always lower than the results of PMA under similar conditions. This is accounted for by the difficulty of the interlayer transmission of the chemical and structural change.

The intercalation of secondary and tertiary amines was also attempted, but the conversion was low. Dodecyl- and benzylamines were intercalated into PMA irrespective of the kind of the precursor ammonium polymers in a high yield, indicating the transformation of the ammonium polymers from the benzyl to dodecylammonium polymer crystals and its reverse. The corresponding $N$-methyl- and $N, N$ -

dimethyl-substituted amines showed low conversions. The steric requirement around the ammonium carboxylate moiety after the reaction is important rather than the basicity of the amines. The secondary and tertiary amines form hydrogen bond networks different from those formed with primary amines, if the reaction could proceed to give ammonium carboxylate polymers. This is one of the reasons for the low reactivity. In the crystals of the primary ammonium salts of PMA and PSA, 2D hydrogen bond network is formed at the interface between the carboxylate anion and countercation layers. Whereas, the construction of another type of hydrogen bond system, possibly a ladder-type hydrogen bond network or a closed-flame hydrogen bond pattern, is expected for secondary and tertiary ammonium crystals, because the style of the hydrogen bond network sensitively depends on the number of hydrogens in the ammonium cation. In other words, PMA or PSA crystals memorize the crystal structure of primary ammonium polymers and recognize the structure of alkylamines. In the reaction with a suitable primary alkylamine fitting the memorized structure of the polymer crystal structure, an intercalation reaction proceeds at a greater rate and reaches a high conversion.

The intercalation of some branched alkylamines was also examined. $n$-Butylamine was intercalated at a high yield independent of the kind of the dispersant when an excess of the amine was used. However, the use of methanol is invalid as the dispersant for the intercalation of branched butylamines due to swelling and dissolution of the polymers or a low conversion. The reaction of PMA with tert-butylamine failed because the resulting tert-butylammonium salt is readily soluble in methanol. Similar results were observed for the PSA intercalation. The reaction in water also induced the swelling of the host PMA or PSA during the reaction, finally resulting in a homogeneous solution. The intercalation of isobutyl- and sec-butylamines also resulted in a lower conversion in various dispersants, differing from the facile intercalation of $n$-butylamine with a linear structure.

Very recently, Odani et al. have found that solventfree intercalation effectively proceeds to give the ammonium polymer crystals in a high conversion. ${ }^{152}$ This is performed in a simple and convenient procedure by grinding the PMA crystals in the presence of a neat amine in a mortar without any solvent. The intercalation proceeded regardless of the kind of the alkylamine used. We have developed solvent-free reactions of the polymer crystal synthesis in each step including monomer synthesis, polymerization, transformation to PMA, and the intercalation, all of which are carried out in the solid state (Scheme 9). 


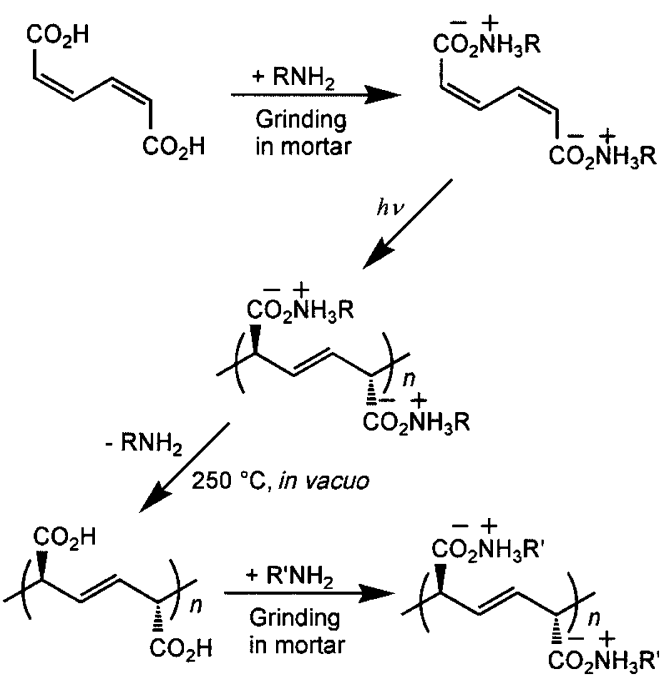

Scheme 9.

The ammonium monomer crystals $\mathbf{2 b}$ and $\mathbf{2 f}$ can be prepared by grinding $(Z, Z)$-muconic acid and the corresponding amines without any solvent in a ceramic mortar. The products were obtained as powdery solids regardless of whether the amine is liquid or solid. The IR spectrum and powder X-ray diffraction profile suggest that the reaction proceeds quantitatively despite a heterogeneous reaction, similar to the monomer crystals prepared by recrystallization. The crystals may change their crystal phase from that of the acid to that of the ammonium salts during the solid-state synthesis. The monomer prepared by the grinding method resulted in a polymer formation in a lower yield compared with that by the recrystallization method under similar photopolymerization conditions in the crystalline state. This is due to the small crystal size (less than $20 \mu \mathrm{m}$ ) of the monomers prepared by the solventfree grinding method. The transformation from the ammonium polymer to PMA was achieved by thermolysis at $250{ }^{\circ} \mathrm{C}$ in vacuo. Solid-state intercalation without any dispersant was also carried out. The solid-state intercalation method enables intercalating sterically hindered amines that cannot be intercalated by the conventional method in methanol because the resulting polymer crystals were soluble. Not only alkylamines but also various other amines including functional groups provide the intercalated ammonium polymers in a high yield via the solid-state intercalation. We also introduced 4-amino-2,2,6,6-tetramethylpiperidine-1-oxyl and 4-(phenylazo)benzylamine as the counter amine into the layered polymer crystals using the solventfree intercalation. The solvent-free intercalation in the solid state is advantageous for the fabrication of layer polymer crystals reacted with sterically hindered alkylamines, when the products tend to dissolve in the solvent used as the dispersant.
Table V summarizes the results for the organic intercalation system using PMA with various amines with a functional group. Aminoalcohols are incorporated in a high yield, irrespective of the position of a hydroxyl group. The polymer crystals modified using optically active alcohols and oligo(oxyethylene)s would be potentially applied to the chiral separation and ionic conductor materials in the future, respectively. The reaction with $\alpha, \omega$-alkanediamines also provides polymer crystals modified by an amino group. In contrast, we failed in the introduction of carboxylic acid using $\alpha, \alpha$ - and $\alpha, \omega$-aminoacids due to the low solubility of aminoacids. The use of water as the dispersant resulted in swelling of the polymers during the reaction. Longchain unsaturated amines are readily intercalated, as had been expected, similarly to the reaction of saturated amines. The ammonium polymer crystals showed an interesting photoreactivity of the side groups, according to the structure of the unsaturated bonds. The oleyl derivative was photoreacted to give an oligomeric product, which was isolated from the polymer crystals after reactions. The diene- and diyne-modified polymer crystals provided a new type of the polymer crystals, in which the stacking layers consist of the PMA anion layers and the countercation layers including polydiene and polydiyne sheets. We are now investigating the application of functionalized polymer crystals, as shown in Figure 17.

In this section, we have shown the fundamental features and mechanism of the intercalation of various alkylamines with PMA and PSA with organic host compounds. The organic intercalation system consisting of layered organic polymers and guest amines has some characteristics different from a large number of known intercalation compounds as the inorganic hosts such as clays, metal phosphonates or phosphites, graphite, metal oxides, and so on. For examples, montmorillonite as a typical clay mineral has negatively charged layers according to the content of $\mathrm{Al}$ and $\mathrm{Mg}$ ions. In the layer, the negative charges delocalize and the charge density is not high. In contrast, the polymer crystals as the organic intercalation host have carboxyl groups orderly arranged along the polymer chains in a high density. This structural feature is potentially used as a new kind of intercalation material for reactions, recognition, separation, and catalysis. Intercalation chemistry dates back to the 1840 s, and the field of intercalation has grown since the 1960s from the chemistry and physics of graphite into various directions of research and applications using other kinds of lamellar host compounds including clays, layered double hydroxides, phosphates, phosphonates, metal chalcogenides, and perovskites. ${ }^{132}$ We believe that our organic 
Table V. Intercalation of functional amines with $\mathrm{PMA}^{\mathrm{a}}$

\begin{tabular}{|c|c|c|c|}
\hline Guest amine & $\frac{\left[-\mathrm{NH}_{2}\right] /\left[-\mathrm{CO}_{2} \mathrm{H}\right]}{\mathrm{mol} / \mathrm{mol}}$ & $\frac{\text { Time }}{\mathrm{h}}$ & $\frac{\text { Conversion }}{\%}$ \\
\hline $\mathrm{H}_{2} \mathrm{~N}\left(\mathrm{CH}_{2}\right)_{2} \mathrm{OH}$ & 10 & 4 & 75 \\
\hline $\mathrm{H}_{2} \mathrm{~N}\left(\mathrm{CH}_{2}\right)_{3} \mathrm{OH}$ & 10 & 2 & 81 \\
\hline $\mathrm{H}_{2} \mathrm{NCH}_{2} \mathrm{CH}_{2} \mathrm{OCH}_{2} \mathrm{CH}_{2} \mathrm{OH}$ & 10 & 4 & 90 \\
\hline $\mathrm{H}_{2} \mathrm{NCH}_{2}\left(\mathrm{CH}_{2} \mathrm{CH}_{2} \mathrm{O}\right)_{3} \mathrm{CH}_{2} \mathrm{CHCH}_{2} \mathrm{NH}_{2}$ & 9 & 2 & 98 \\
\hline$(R S)-\mathrm{H}_{2} \mathrm{NCH}_{2} \mathrm{CHOHCH}_{3}$ & 2 & 24 & 82 \\
\hline$(R)-\mathrm{H}_{2} \mathrm{NCH}_{2} \mathrm{CHOHCH}_{3}$ & 2 & 48 & 89 \\
\hline $\mathrm{H}_{2} \mathrm{~N}\left(\mathrm{CH}_{2}\right)_{6} \mathrm{NH}_{2}$ & 10 & 24 & 84 \\
\hline$(9 \mathrm{Z})-\mathrm{H}_{2} \mathrm{~N}\left(\mathrm{CH}_{2}\right)_{8} \mathrm{CH}=\mathrm{CH}\left(\mathrm{CH}_{2}\right)_{7} \mathrm{CH}_{3}$ & 1 & 1 & 94 \\
\hline$(2 E, 4 E)-\mathrm{H}_{2} \mathrm{NCH}_{2} \mathrm{CHCCHCH}=\mathrm{CH}\left(\mathrm{CH}_{2}\right)_{8} \mathrm{CH}_{3}$ & 5 & 8 & 87 \\
\hline $\mathrm{H}_{2} \mathrm{~N}\left(\mathrm{CH}_{2}\right)_{9} \mathrm{C} \equiv \mathrm{CC} \equiv \mathrm{C}\left(\mathrm{CH}_{2}\right)_{11} \mathrm{CH}_{3}$ & 2 & 24 & 77 \\
\hline $\mathrm{H}_{2} \mathrm{NC}\left(\mathrm{CH}_{3}\right)_{2} \mathrm{CH}_{2} \mathrm{C}\left(\mathrm{CH}_{3}\right)_{3}$ & $1^{\mathrm{b}}$ & 0.5 & 56 \\
\hline 4-Amino-TEMPO & $1^{\mathrm{b}}$ & 0.5 & 47 \\
\hline $\mathrm{H}_{2} \mathrm{NCH}_{2} \mathrm{C}_{6} \mathrm{H}_{4} \mathrm{~N}=\mathrm{NC}_{6} \mathrm{H}_{5}$ & $3(1)^{b}$ & $36(0.5)^{\mathrm{b}}$ & $81(48)^{\mathrm{b}}$ \\
\hline
\end{tabular}

${ }^{\mathrm{a}}$ In methanol as the dispersant. ${ }^{\mathrm{b}}$ Solid-state organic intercalation.

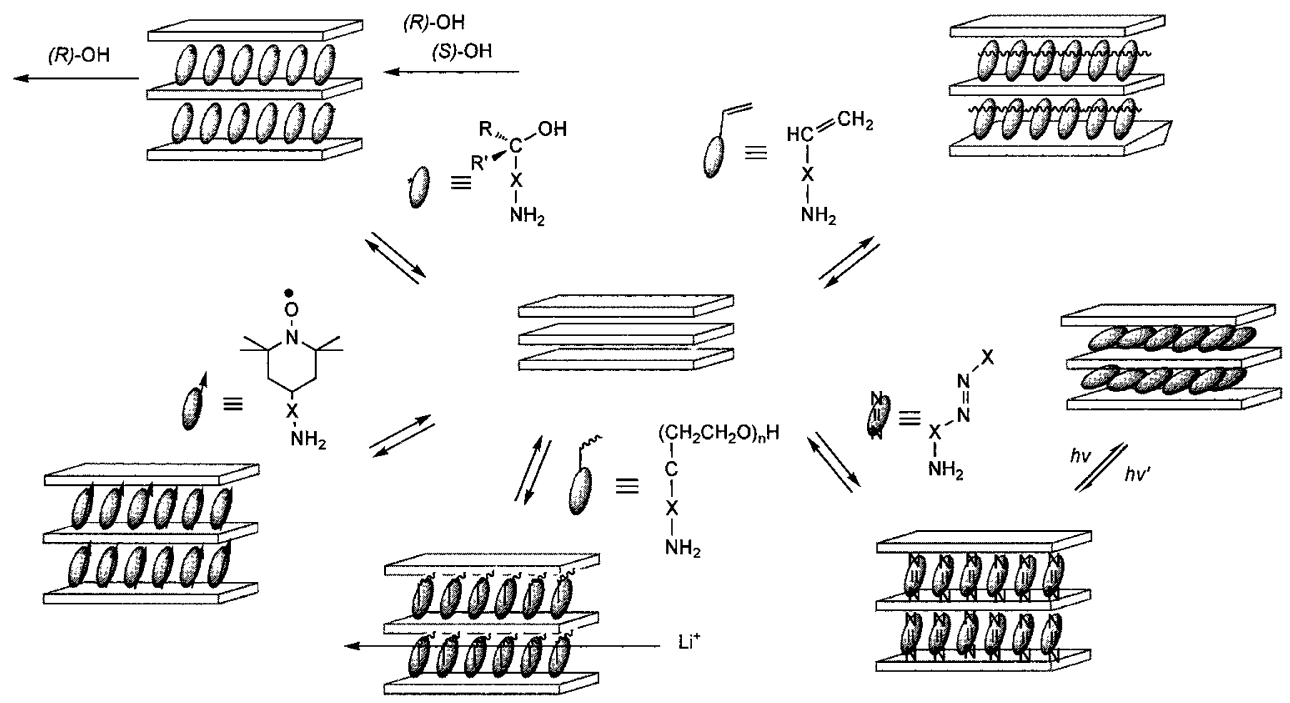

Figure 17. Fabrication of functional polymer crystals by organic intercalation using layered polymer crystals with various functional amines.

polymer hosts are added to the lineup of intercalation hosts as a new member and are expected to develop into a new field of intercalation chemistry and material science.

\section{CONCLUSION}

For the topochemical polymerization of 1,3-diene monomers, the packing structure of the monomers in the crystals is important to control the polymerization reactivity. By the combination of several strong and weak intermolecular interactions, we are now able to access a rational design of the crystal structure and the crystalline-state polymerizations. We have proposed principles for the topochemical polymerization of 1,3diene monomers in order to predict the polymerization reactivity and design crystalline polymer materials. In the crystals of polymerizable monomers, diene molecules stack in a columnar structure with an exclusively limited stacking distance of $5 \AA$, which is close to the repeating distance of the monomer units in the resulting polymer chain and is appropriate for the polymerization via a topochemical reaction mechanism. We have also shown supramolecular synthons for constructing the desired monomer stacking in the crystals using weak intermolecular interactions such as the $2 \mathrm{D}$ hydrogen bond network, aromatic ring stacking, $\mathrm{CH} / \pi$, $\mathrm{CH} / \mathrm{O}$, and halogen-halogen interactions. Recently, some examples for new kinds of topochemical and solid-state polymerizations have been reported. ${ }^{153-160}$ Polymer syntheses in the solid state will become more important in the future.

The arrangement of monomer molecules in a column structure with a stacking distance of $5 \AA$ results in a successful topochemical polymerization, but limited monomers actually induce the topochemical polymer- 
ization in the crystalline state. Because of the structural limit for the topochemical polymerization, it is difficult to design the monomer crystals with a specific functional group without losing the topochemical polymerization ability. Therefore, intercalation has great potential for the introduction of various functional groups to induce not only a change in crystal structure but also chemical reactions, molecular recognition, separation, and physical interactions. Fundamental features and mechanism have already been investigated for the organic intercalation system using PMA and PSA as the host polymer crystals.

In recent years, the concept of green sustainable chemistry was proposed and many approaches to environmentally benign organic synthesis have been reported. ${ }^{161}$ Among the twelve principles of green chemistry, it is noted that the use of auxiliary substances, for example, solvents and separation agents, should be eliminated whenever possible and should be innocuous when used. The reactions in the solid state are one of the environmentally benign reactions in terms of unnecessary solvents. Many kinds of organic reactions proceed even in the solid state similar to those in solution. ${ }^{162-167}$ We have also demonstrated a totally solvent-free process for the synthesis of polymer crystals using $(Z, Z)$-muconic acid as the starting material. All the reactions in four steps of the process, that is, monomer synthesis, polymerization, transformation to PMA, and intercalation, proceeded in the solid state as well as in the conventional method using solvents and dispersants. The starting muconic acid is a metabolite of benzene and related aromatic compounds. Recently, the environmentally benign synthesis of the starting

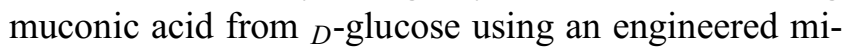
crobe was reported. ${ }^{168,169}$ The system described here is a new type of polymer synthesis using a green material as the starting compound and the solvent-free process. The polymer crystals obtained by topochemical polymerization and the subsequent organic intercalation are expected to be used as advanced organic materials in various fields.

Acknowledgment. The author acknowledges Dr. Toshihiro Tanaka, Dr. Toru Odani, Mr. Sadamu Nagahama, and the other members of the research group of Osaka City University. He deeply thanks Dr. Kazuki Sada, Kyushu Univeristy, Prof. Mikiji Miyata, and Prof. Kohji Tashiro, Osaka University, for their continuous collaboration and invaluable discussions, and Dr. Kunio Oka, Osaka Prefecture University for the radiation experiments. This work was financially supported by the Japan Science and Technology Corporation (JST) and by Grant-in-Aids from the Ministry of Education,
Culture, Sports, Science and Technology of Japan.

\section{REFERENCES}

1. A.-D. Schlüter, Ed., "Synthesis of Polymers", Wiley-VCH, Weinheim, 1999.

2. V. Percec, Guest Ed., Chem. Rev., Thematic issue on Frontiers in Polymer Chemistry, vol. 101, no. 12, pp 3579-4192 (2001).

3. K. Tajima and T. Aida, Chem. Commun., 2000, 2399.

4. A.-D. Schlüter and J. P. Rabe, Angew. Chem. Int. Ed., 39, 864 (2000).

5. M. Alexander and P. Dubois, Mater. Sci. Eng., R, Reports, 28, 1 (2000).

6. V. Percec and M. N. Holerca, Biomacromolecules, 1, 6 (2000).

7. A. Stein, B. J. Melde, and R. C. Schroden, Adv. Mater., 12, 1403 (2000).

8. A. P. Alivisatos, P. F. Barbara, A. W. Castleman, J. Chang, D. A. Dixon, M. L. Klein, G. L. McLendon, J. S. Miller, M. A. Ratner, P. J. Rossky, S. I. Stupp, and M. E. Thompson, Adv. Mater., 10, 1297 (1998).

9. K. Matyjaszewski and J. Xia, Chem. Rev., 101, 2921 (2001).

10. A. J. Berresheim, M. Muller, and K. Mullen, Chem. Rev., 99, 1747 (1999).

11. T. M. Swager, in "Organised Molecular Assemblies in the Solid State”, J. K. Whitesell, Ed., John Wiley \& Sons, Chichester, 1999, chapt. 2, p 39.

12. G. Natta and F. Danusso, Ed., "Stereoregular Polymers and Stereospecific Polymerizations: The Contribution of Gulio Natta and his School to Polymer Chemistry", vol. 1 and 2, Pergamon Press, Oxford, 1967.

13. J. Boor, Jr., "Ziegler-Natta Catalysts and Polymerizations", Academic Press Inc., New York, N.Y., 1979.

14. M. Farina, Top. Stereochem., 17, 1 (1987).

15. G. Moad and D. H. Solomon, "The Chemistry of Free Radical Polymerization”, Pergamon, Oxford, 1995.

16. K. Matyjaszewski and T. P. Davis, Ed., "Handbook of Radical Polymerization”, John Wiley \& Sons, Inc., New York, N.Y., 2002.

17. K. Matyjaszewski, Ed., "Controlled/Living Radical Polymerization", ACS Symposium Series 768, American Chemical Society, Washington, D.C., 2000.

18. T. Otsu and A. Matsumoto, Adv. Polym. Sci., 136, 75 (1998).

19. T. Otsu, J. Polym. Sci., Part A, Polym. Chem., 38, 2121 (2000).

20. A. Matsumoto, in ref 17, chapt. 13, p 691.

21. D. P. Curran, N. A. Porter, and B. Giese, "Stereochemistry of Radical Reactions", VCH, Weinheim, 1996.

22. P. Renaud and M. P. Sibi, Eds., "Radicals in Organic Synthesis", vol. 1 and 2, Wiley-VCH, Weinheim, 2001.

23. Y. Chatani, Prog. Polym. Sci., Japan, 7, 149 (1974).

24. G. Wegner, Pure Appl. Chem., 49, 443 (1977).

25. V. Enkelmann, Adv. Polym. Sci., 63, 91 (1984).

26. M. Hasegawa, Adv. Phys. Org. Chem., 30, 117 (1995).

27. J. F. Brown, Jr. and D. M. White, J. Am. Chem. Soc., 82, 5671 (1960).

28. M. Farina, "Encyclopedia of Polymer Science and Engineer- 
ing”, J. I. Kroschwitz, Ed., vol. 12, John Wiley \& Sons, Inc., New York, N.Y., 1988, p 486.

29. K. Takemoto and M. Miyata, J. Macromol. Sci., Rev. Macromol. Chem. Phys., C18, 83 (1980).

30. M. Miyata, in "Comprehensive Supramolecular Chemistry", vol. 10, N. D. Reinhoudt, Ed., Pergamon, Oxford, 1996, p 557.

31. B. Tieke and G. Wegner, Angew. Chem. Int. Ed. Eng., 20, 687 (1981)

32. B. Tieke, J. Polym. Sci., Polym. Chem. Ed., 22, 391 (1984).

33. B. Tieke and G. Chapuis, J. Polym. Sci., Polym. Chem. Ed., 22, 2895 (1984).

34. B. Tieke, Adv. Polym. Sci., 71, 79 (1985)

35. B. Tieke, in "Polymerization in Organized Media", C. M. Paleos, Ed., Gordon and Breach Science Publishers S. A., Philadelphia, PA, 1992, p 105.

36. B. Tieke, Colloid Polym. Sci, 263, 965 (1985).

37. A. Matsumoto, Prog. React. Kinet. Mech., 26, 59 (2001).

38. A. Matsumoto and T. Odani, Macromol. Rapid Commun., 22, 1195 (2001).

39. A. Matsumoto, T. Matsumura, and S. Aoki, J. Chem. Soc., Chem. Commun., 1994, 1389.

40. A. Matsumoto, T. Matsumura, and S. Aoki, Macromolecules, 29, 423 (1996).

41. A. Matsumoto, K. Yokoi, S. Aoki, K. Tashiro, T. Kamae, and M. Kobayashi, Macromolecules, 31, 2129 (1998).

42. A. Matsumoto, T. Tanaka, T. Tsubouchi, K. Tashiro, S. Saragai, and S. Nakamoto, J. Am. Chem. Soc., 124, 8891 (2002).

43. T. Tanaka and A. Matsumoto, J. Am. Chem. Soc., 124, 9676 (2002).

44. A. Matsumoto, T. Odani, and S. Aoki, Polym. J., 30, 358 (1998).

45. A. Matsumoto, T. Odani, and K. Yokoi, Proc. Jpn. Acad. Ser. $B, \mathbf{7 4}, 110$ (1998).

46. A. Matsumoto, T. Odani, M. Chikada, K. Sada, and M. Miyata, J. Am. Chem. Soc., 121, 11122 (1999).

47. T. Odani and A. Matsumoto, Macromol. Rapid Commun., 21, 40 (2000).

48. A. Matsumoto, S. Nagahama, and T. Odani, J. Am. Chem. Soc., 122, 9109 (2000).

49. A. Matsumoto and T. Odani, Polym. J., 31, 717 (1999).

50. A. Matsumoto, K. Sada, K. Tashiro, M. Miyata, T. Tsubouchi, T. Tanaka, T. Odani, S. Nagahama, T. Tanaka, K. Inoue, S. Saragai, and S. Nakamoto, Angew. Chem. Int. Ed., 41, 2502 (2002)

51. A. Matsumoto, T. Chiba, and K. Oka, Macromolecules, submitted.

52. S. M. Schlitter and H. P. Beck, Chem. Ber., 129, 1561 (1996).

53. A. I. Kitaigorodskii, "Molecular Crystals and Molecules", Academic Press Inc., New York, N.Y., 1973.

54. A. I. Kitaigorodskii, "Mixed Crystals", Solid-State Science, vol. 33, Springer, Berlin, 1984.

55. A. Gavezzotti, Acc. Chem. Res., 27, 309 (1994).

56. A. Gavezzotti, Synlett, 2002, 201.

57. G. R. Desiraju, Nature Mater, 1, 77 (2002).

58. G. R. Desiraju, "Crystal Engineering: The Design of Organic Solids", Elsevier Science Publishers B. V., Amsterdam, 1989.

59. G. R. Desiraju, Ed., "The Crystal as a Supramolecular En- tity: Perspective in Supramolecular Chemistry", vol. 2, Jhon Wiley \& Sons Ltd., Chichester, 1995.

60. G. R. Desiraju, Nature, 412, 397 (2001).

61. J. W. Steed and J. L. Atwood, "Supramolecular Chemistry", John Wiley \& Sons Ltd., Chichester, 2000, p 389.

62. D. D. MacNicol, F. Toda, and R. Bishop, Eds., "Comprehensive Supramolecular Chemistry", vol. 6, Solid State Supramolecular Chemistry: Crystal Engineering, Pergamon, Oxford, 1996.

63. K. Tashiro, T. Kamae, M. Kobayashi, A. Matsumoto, K. Yokoi, and S. Aoki, Macromolecules, 32, 2449 (1999).

64. A. Matsumoto, K. Katayama, T. Odani, K. Oka, K. Tashiro, S. Saragai, and S. Nakamoto, Macromolecules, 33, 7786 (2000).

65. S. Nagahama and A. Matsumoto, Chem. Lett., 2002, 1026.

66. M. Augenstein and G. Wegner, Makromol. Chem., 189, 163 (1984).

67. K. Tashiro, A. N. Zadorin, S. Saragai, T. Kamae, A. Matsumoto, K. Yokoi, and S. Aoki, Macromolecules, 32, 7946 (1999).

68. S. Nakamoto, K. Tashiro, and A. Matsumoto, Macromolecules, 36, 109 (2003).

69. S. Saragai, K. Tashiro, S. Nakamoto, T. Kamae, A. Matsumoto, and T. Tsubouchi, Polym. J., 33,199 (2001).

70. S. Saragai, K. Tashiro, S. Nakamoto, A. Matsumoto, and T. Tsubouchi, J. Phys. Chem. B, 105, 4155 (2001).

71. G. W. Coates, A. R. Dunn, L. M. Henling, D. A. Dougherty, and R. H. Grubbs, Angew. Chem. Int. Ed., 36, 248 (1997).

72. G. W. Coates, A. R. Dunn, L. M. Henling, J. W. Ziller, E. B. Lobkovsky, and R. H. Grubbs, J. Am. Chem. Soc., 120, 3641 (1998).

73. G. R. Desiraju, Angew. Chem. Int. Ed. Eng., 34, 2311 (1995).

74. G. A. Jeffrey, "An Introduction to Hydrogen Bonding", Oxford University Press, Oxford, 1997.

75. M. C. Etter, Acc. Chem. Res., 23, 120 (1990).

76. J. C. MacDonald and G. M. Whitesides, Chem. Rev., 94, 2383 (1994).

77. R. E. Meléndez and A. D. Hamilton, Top. Curr. Chem., 198, 97 (1998).

78. K. T. Holman, A. M. Pivovar, J. A. Swift, and M. D. Ward, Acc. Chem. Res., 34, 107 (2001).

79. B. Moulton and M. J. Zaworotko, Chem. Rev., 101, 1629 (2001).

80. A. M. Beatty, Cryst. Eng. Comm., 51, 1 (2001).

81. M. Nishio, M. Hirota, and Y. Umezawa, "The $\mathrm{CH} / \pi$ Interaction: Evidence, Nature, and Consequences”, John Wiley \& Sons, Inc., New York, N.Y., 1998.

82. G. R. Desiraju and T. Steiner, "The Weak Hydrogen Bond in Structural Chemistry and Biology", Oxford University Press, Oxford, 1999.

83. G. R. Desiraju, Acc. Chem. Res., 35, 565 (2002).

84. G. R. Desiraju, Acc. Chem. Res., 29, 441 (1996).

85. S. Nagahama, K. Inoue, K. Sada, M. Miyata, and A. Matsumoto, Cryst. Growth Design, in press (Web Release Data: February 8, 2003).

86. T. Odani, A. Matsumoto, K. Sada, and M. Miyata, Chem. Commun., 2001, 2004.

87. G. W. Coates, Chem. Rev., 100, 1223 (2000).

88. K. Hatada and T. Kitayama, Polym. Int., 49, 11 (2000). 
89. K. Soga and T. Shiono, Prog. Polym. Sci., 22, 1503 (1997).

90. H. Yasuda and E. Ihara, Adv. Polym. Sci., 133, 53 (1997).

91. Y. Tanaka, Kobunshi, 40, 88 (1991).

92. W. M. Saltman and T. H. Link, Ind. Eng. Chem., Prod. Res. Dev., 3, 199 (1964).

93. M. Gippin, Ind. Eng. Chem., Prod. Res. Dev., 1, 32 (1962).

94. G. Lugli, A. Mazzei, and S. Poggio, Makromol. Chem., 175, 2021 (1974).

95. S. Kaita, Z. Hou, and Y. Wakatsuki, Macromolecules, 32, 9078 (1999).

96. G. Natta, L. Porri, P. Corradini, and D. Morero, Chim. Ind. (Milan), 40, 362 (1958).

97. D. K. Jenkins, Polymer, 26, 147 (1985).

98. G. Natta, L. Porri, G. Zanini, and L. Fiore, Chim. Ind. (Milan), 41, 526 (1959).

99. H. Ashitaka, K. Inaishi, and H. Ueno, J. Polym. Sci., Polym. Chem. Ed., 21, 1973 (1983).

100. A. F. Halasa, D. F. Lohr, and J. E. Hall, J. Polym. Sci., Polym. Chem. Ed., 19, 1357 (1981).

101. G. Natta, M. Farina, and M. Donati, Makromol. Chem., 43, 251 (1961).

102. M. Donati, G. Perego, and M. Farina, Makromol. Chem., 85, 301 (1965)

103. A. Takasu, M. Ishii, Y. Inai, and T. Hirabayashi, Macromolecules, 34, 6548 (2001).

104. M. Farina, G. Natta, G. Allegra, and M. Löffelholz, J. Polym. Sci., Part C, 16, 2517 (1967).

105. M. Farina, G. Audisio, and G. Natta, J. Am. Chem. Soc., 89, 5071 (1967).

106. N. Ishihara, M. Seimiya, M. Kuramoto, and M. Uoi, Macromolecules, 19, 2465 (1986).

107. J. A. Ewen, R. L. Jones, A. Razavi, and J. D. Ferrara, J. Am. Chem. Soc., 110, 6255 (1988).

108. T. Kitayama, E. Masuda, M. Yamaguchi, T. Nishiura, and K. Hatada, Polym. J., 24, 817 (1992).

109. H. Yasuda, H. Yamamoto, M. Yamashita, K. Yokota, A. Nakamura, S. Miyake, Y. Kai, and N. Kanehisa, Macromolecules, 26, 7134 (1993).

110. K. Ute, T. Asada, Y. Nabeshima, and K. Hatada, Polym. Bull., 30, 171 (1993).

111. K. Ute, T. Tarao, S. Honjo, H. Ohnuma, K. Hatada, and T. Kitayama, Polym. J., 31, 177 (1999).

112. T. Odani and A. Matsumoto, Cryst. Eng. Comm., 4, 467 (2002).

113. B. R. Penfold, Acta Crystallogr., 6, 591 (1953).

114. M. Simard, D. Su, and J. D. Wuest, J. Am. Chem. Soc., 113, 4696 (1991).

115. C. B. Aakeröy, A. M. Beatty, M. Nieuwenhuyzen, and M. Zou, Tetrahedron, 56, 6693 (2000).

116. A. Matsumoto, Y. Ishizu, and K. Yokoi, Macromol. Chem. Phys., 199, 2511 (1998).

117. A. Matsumoto and H. Higashi, Macromolecules, 33, 1651 (2000).

118. H. Hatakenaka, Y. Takahashi, and A. Matsumoto, to be submitted.

119. R. Iida, H. Kasai, S. Okada, H. Oikawa, H. Matsuda, A. Kakuta, and H. Nakanishi, Mol. Cryst. Liq. Cryst., 267, 95 (1995).

120. K. Tashiro, S. Nakamoto, S. Saragai, A. Matsumoto, and T.
Tsubouchi, Polymer, 42, 6747 (2001).

121. A. Matsumoto, K. Yokoi, and S. Aoki, Polym. J., 30, 361 (1998).

122. A. Matsumoto and K. Yokoi, J. Polym. Sci., Part A, Polym. Chem., 36, 3147 (1998).

123. A. Matsumoto and S. Nagahama, Proc. Jpn. Acad. Ser. B, 77, 110 (2001).

124. A. -D. Schlüter, in ref 1, p 459.

125. A. -D. Schlüter, M. Löffler, and V. Enkelmann, Nature, 368, 831 (1994).

126. U. Scherf and K. Müllen, Adv. Polym. Sci., 123, 1 (1995).

127. S. Okada, K. Hayamizu, H. Matsuda, A. Masaki, N. Ninami, and H. Nakanishi, Macromolecules, 27, 6259 (1994).

128. B. Dinkelmeyer, J. W. Lauher, and F. W. Fowler, Mol. Cryst. Liq. Cryst., 313, 259 (1998).

129. H. Matsuzawa, S. Okada, A. Sarkar, H. Nakanishi, and H. Matsuda, J. Polym. Sci., Part A, Polym. Chem., 37, 3537 (1999).

130. S. Nagahama and A. Matsumoto, J. Am. Chem. Soc., 123, 12176 (2001).

131. M. S. Whittingham, A. J. Jacobsen, Eds., "Intercalation Chemistry”, Academic Press, New York, N.Y., 1982.

132. G. Alberti and T. Bein, Ed., "Comprehensive Supramolecular Chemistry", vol. 7, Solid-State Supramolecular Chemistry: Two- and Three-Dimensional Inorganic Networks", Pergamon, Oxford, 1996.

133. G. Lagaly and K. Beneke, Colloid Polym. Sci., 269, 1198 (1991).

134. S. Komarneni, J. Mater. Chem., 2, 1219 (1992).

135. E. Ruizhitzky, Adv. Mater., 5, 334 (1993).

136. D. O'Hare, New J. Chem., 18, 989 (1994).

137. A. Okada and A. Usuki, Mater. Sci. Eng. C, 3, 109 (1995).

138. P. Judeinstein and C. Sanchez, J. Mater. Chem., 6, 511 (1996).

139. M. Ogawa and K. Kuroda, Bull. Chem. Soc. Jpn., 70, 2593 (1997).

140. T. E. Mallouk and J. A. Gavin, Acc. Chem. Res., 31, 209 (1998).

141. J. M. Terascon and M. Armand, Nature, 414, 359 (2000).

142. A. W. Coleman, S. G. Bott, S. D. Morley, C. M. Means, K. D. Robinson, H. Zhang, and J. L. Atwood, Angew. Chem. Int. Ed. Eng., 27, 1361 (1988).

143. J. L. Atwood, F. Hamada, K. D. Robinson, G. W. Orr, and R. L. Vincent, Nature, 349, 683 (1991).

144. M. Miyata, M. Shibakami, S. Chirachanchai, K. Takemoto, N. Kasai, and K. Miki, Nature, 343, 446 (1990).

145. K. Sada, M. Sugahara, K. Kato, and M. Miyata, J. Am. Chem. Soc., 123, 4386 (2001).

146. K. Biradha, D. Dennis, V. A. MacKinnon, C. V. K. Sharma, and M. J. Zaworotko, J. Am. Chem. Soc., 120, 11894 (1998).

147. J. A. Swift, A. M. Pivovar, A. M. Reynolds, and M. D. Ward, J. Am. Chem. Soc., 120, 5887 (1998).

148. M. D. Ward and A. M. Pivovar, Curr. Opin. Solid State Mater. Sci., 4, 581 (1999).

149. A. Matsumoto, T. Odani, K. Sada, M. Miyata, and K. Tashiro, Nature, 405, 328 (2000).

150. M. D. Ward, Nature, 405, 293 (2000).

151. A. Matsumoto, S. Oshita, and D. Fujioka, J. Am. Chem. Soc., 124, 13749 (1998). 
152. T. Odani and A. Matsumoto, Polym. J., 34, 846 (2002).

153. J. Xiao, M. Yang, J. W. Lauher, and F. W. Fowler, Angew. Chem. Int. Ed., 39, 2132 (2000).

154. T. Hoang, J. W. Lauher, and F. W. Fowler, J. Am. Chem. Soc., 124, 10656 (2002).

155. T. Itoh, S. Nomura, T. Uno, M. Kubo, K. Sada, and M. Miyata, Angew. Chem. Int. Ed., 41, 4306 (2002).

156. R. Nagahata, J. Sugiyama, M. Goyai, M. Asai, M. Ueda, and K. Takeuchi, J. Polym. Sci., Part A, Polym. Chem., 38, 3360 (2000).

157. A. Kameyama, K. Kimura, and T. Nishikubo, J. Polym. Sci., Part A, Polym. Chem., 39, 951 (2001).

158. M. Suzuki and Y. Yatsugi, Chem. Commun., 2002, 162.

159. T. Sasaki, K. Hayashibara, and M. Suzuki, Macromolecules, 36, 279 (2003).

160. K. Kimura, S. Kohama, and Y. Yamashita, Macromolecules, 35, 7545 (2002).

161. R. T. Anastas and J. C. Warnar, "Green Chemistry: The- ory and Practice", Oxford University Press, New York, N.Y., 1998.

162. G. M. J. Schmidt, Pure Appl. Chem., 27, 647 (1971).

163. V. Ramamurthy, Ed., "Photochemistry in Organized and Constrained Media", VCH Publishers, New York, N.Y., 1991.

164. Y. Ohashi, Ed., "Reactivity in Molecular Crystals", Kodansha Ltd., Tokyo, 1993.

165. F. Toda, Acc. Chem. Res., 28, 480 (1995).

166. K. Tanaka and F. Toda, Chem. Rev., 100, 1025 (2000).

167. F. Toda, Ed., "Organic Solid-State Reactions", Kluwer Academic Publishers, Dordrecht, 2002.

168. K. M. Draths and J. W. Frost, in "Green Chemistry: Frontiers in Benign Chemical Synthesis and Processes", R. T. Anastas and T. C. Williamson, Eds., Oxford University Press, New York, N.Y., 1998, chapt. 9, p 150.

169. K. M. Draths and J. W. Frost, J. Am. Chem. Soc., 112, 9630 (1990).

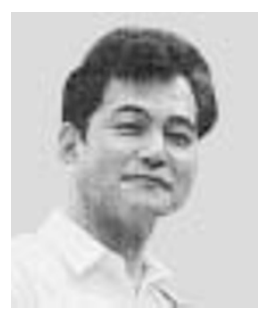

Akikazu Matsumoto was born in Osaka in 1959. He received his Ph.D in 1991 from Osaka City University on polymer synthesis by radical polymerization of $N$-substituted maleimides. In 1985, he had already started an academic career in the Department of Applied Chemistry, Osaka City University as an assistant professor. During 1994-1995, he worked on free-radical chemistry as a research fellow at the University of Basel, Switzerland, with Professor Bernd Giese. He was promoted to Associate Professor in 1999. He is also a researcher for PRESTO-JST in the research area of Conversion and Control by Advanced Chemistry during 2000-2003. He is the recipient of The Wiley Polymer Science Award (Chemistry) 2002 from the Society of Polymer Science, Japan. His research interests cover controlled synthesis of polymers, crystal engineering, solid-state organic reactions, topologically designed polymers, as well as the kinetics and mechanism of radical reactions and polymerization. 